Chapter 18

\title{
HIV-2 Interaction with Target Cell Receptors, or Why HIV-2 is Less Pathogenic than HIV-1
}

\author{
José Miguel Azevedo-Pereira \\ Additional information is available at the end of the chapter \\ http://dx.doi.org/10.5772/53201
}

\section{Introduction}

Although sharing identical transmission routes as well as structural and genomic properties, human immunodeficiency viruses 1 and 2 (HIV-1 and HIV-2, respectively) show different pathogenic abilities in human host. Despite both HIV-1 and HIV-2 lead to immunological failure and Acquired Immunodeficiency Syndrome (AIDS), a slower rate of disease progression with a longer asymptomatic period and lower levels of viremia in general characterize HIV-2 infection (Table 1). Comparative studies measuring the progression rates of both HIV-1 and HIV-2 infections provided clear evidence that the majority of HIV-2 infected individuals fit in a definition of long-term non-progressors [1-3].

\begin{tabular}{lll}
\hline & HIV-1 & HIV-2 \\
\hline Geographic distribution & Worldwide & $\begin{array}{l}\text { Restricted to West African countries and to } \\
\text { countries sharing economical-social links with them }\end{array}$ \\
\hline Viral load & Usually moderate to high & Usually undetectable \\
\hline Transmission & By sexual route is usually inefficient, requiring & Scarce data but less efficiently transmitted than \\
& multiple exposures & HIV-1 \\
\hline Duration of asymptomatic & Usually less than 10 years & Usually decades \\
stage & Plenty of data regarding viral susceptibility to & Naturally resistant to non-nucleoside analogous \\
Treatment & all anti-retroviral drugs. Resistance-conferring & targeting reverse transcriptase. Scarce and \\
& mutations well established and defined & sometimes conflicting results regarding \\
& & susceptibility to other anti-retroviral drugs \\
\hline
\end{tabular}

Table 1. Comparison between epidemiologic and clinical data of HIV-1 and HIV-2 infections 
All these findings support the notion that in HIV-2 infected individuals several factors (e.g. virologic and immunologic) should account for a best fitted response that ultimately leads to a better control of HIV-2 infection compared to HIV-1. Deciphering these factors should provide crucial information about the mechanisms underlying the delayed disease progression and may help explain how a retroviruses infection could be coped for such a long time without causing disease. This knowledge is important to clarify AIDS pathogenesis and to identify the correlates of protection crucial to develop an efficient HIV vaccine.

Despite the potential importance of HIV-2 as a model to address those issues, it has been mostly neglected and very few data exists regarding HIV-2 interaction with target cells. In this chapter I will focus on these interactions, particularly those concerning early events. Distinguishing features between HIV-1 and HIV-2 will be highlighted and their implications in viral fitness and pathogenic differences between the two viruses will be discussed.

\section{Origin of HIV-2}

HIV-2, as HIV-1, belongs to Family Retroviridae, Subfamily Orthoretrovirinae, Genus Lentivirus [4]. It was first isolated from a symptomatic patient from Guinea-Bissau [5] and subsequently associated with immunological failure and clinical manifestations typically observed in AIDS patients infected with HIV-1 [6].

HIV-1 and HIV-2 were introduced into human population as a consequence of multiple crossspecies transmissions from simian immunodeficiency virus (SIV)-infected non-human primates. The genetic relatedness between HIV-1, HIV-2 and SIV strains, and the coincidence of natural habitats of specific simian species and geographic regions where HIV-1 and HIV-2 had probably emerged, allowed the identification of SIVcpz (infecting the chimpanzee subspecies Pan troglodytes troglodytes) and SIVsm (infecting sooty mangabey subspecies Cercocebus atys) as viral ancestors of HIV-1 and HIV-2, respectively [7-9]. Through a combination of phylogenetic and molecular clock analysis it was estimated that the date of the most recent common ancestor of HIV-1 group M was $1930 \pm 15$, and that of "HIV-2 group A was $1940 \pm 16[8,10]$. These cross-species transmission events was then fuelled-up by social, sexual and iatrogenic factors during colonial period in Africa [11], converting a restricted zoonotic disease into an epidemic (HIV-2) and pandemic (HIV-1) infections.

\section{Genomic organization of HIV-2}

The genomic information of HIV-2 is comprised in two identical copies of $9.2 \mathrm{~kb}$ single strand RNA. HIV-2 genome encodes nine open reading frames (i.e. gag, pol, vif, vpr, tat, rev, opx, env and nef), flanked by two long terminal repeats (5'LTR and 3'LTR). Soon after entry into target cell the genomic RNA is converted to a double-stranded DNA molecule, a reaction catalized by reverse transcriptase (RT) enzyme, that occurs in a cytoplasmic complex, named reverse transcriptase complex (RTC). The RTC transforms 
to the preintegration complex (PIC) composed by several cellular and viral components, e.g. viral DNA, RT, integrase (IN), matrix (MA) and Vpr proteins (reviewed in [12]). This PIC allows the reverse transcribed viral DNA to enter the nucleus through the nuclear pore and to be integrated into the genome of target cell.

After integration, the HIV-2 proviral DNA is transcribed into several mRNAs by cellular RNA polymerase II, a process initiated through the binding of cellular activation factors to the viral LTR, culminating in the synthesis of viral proteins and in the production of new progeny virions. The function of each HIV-2 protein has been inferred from HIV-1 counterparts and reviewed in [13].

Compared to HIV-1, HIV-2 lacks the $v p u$ gene while has the $v p x$ gene. The Vpu protein has been associated with two main functions in HIV-1 replication: induces a rapid degradation of CD4 molecules (see below the role of CD4 as viral receptor) in endoplasmic reticulum through the ubiquitin-proteasome system [14]; and enhancing the budding and release of viral particles [15] by counteracting the activity of Tetherin/BST2, a cellular factor that restricts the egress of enveloped viruses (e.g. HIV, Ebola virus), thereby reducing viral production and cell-free virus propagation [16, 17]. In HIV-2, this latter role in viral replication seems to be assumed by the membrane-anchored subunit and the extracellular domain of transmembrane (TM) envelope glycoprotein $[18,19]$.

Vpx is a protein only present in HIV-2 and SIVsm lineage. Sequence analysis suggests that the vpx gene is a duplication of $v p r$ gene but despite amino acid sequence similarities between both proteins, their functions are clearly distinct. While $\mathrm{Vpr}$ is mainly involved in cell cycle arrest in G2/M phase [20], the Vpx protein has been recently linked to the enhancement of HIV-1 infection of dendritic cells and an essential factor in innate response to HIV infection [21]. The obvious importance of $\mathrm{Vpx}$ in the pathogenesis of human lentiviral infection will be further discussed in subchapters 4 and 5 .

\section{HIV-2 as a limited spreading virus}

As in all zoonosis, the emergence of HIV-1 and HIV-2, as successful new human pathogens, involved not only a close contact with animal reservoirs but also the capability of the crossspecies viruses to: encounter and efficiently infect human host cells, and to be able to be effectively transmitted within the human population.

Although HIV-1 and HIV-2 shared common transmission routes, they show a clear distinct epidemiology. While HIV-1, particularly group $M$, has spread literally worldwide, HIV-2 infection reveal a much more confined geographic distribution: West Africa and countries that maintained social-economic links to this region (e.g. Portugal, France and their former colonies). Since both viruses had begun to spread nearly at the same time, somewhere between 1950 and 1970, this limited expansion of HIV-2 indicates a less efficient human transmission. Heterosexual spread of HIV-2 is remarkably lower than in HIV-1: it seems that HIV-2 is five to nine times less efficiently transmitted than HIV-1 by sexual route [22]. Likewise, mother-to- 
child transmission rate of HIV-2 is $0-4 \%$, while in HIV-1 this transmission occurs in $15-40 \%$ of untreated pregnancies [23].

This poor capability to infect new hosts could lead HIV-2 to a dead end. Viral ecology imposes two ideal conditions: maintain the host alive as long as possible while being efficiently transmitted within host population. HIV-2 only fulfils the first condition leading to a decline in HIV-2 prevalence even in regions (i.e. West Africa) where, in the early stages of AIDS epidemic, a clear predominance of HIV-2 infections existed compared to HIV-1 [24].

\subsection{Viral load and transmission}

Many different factors account for a successful transmission of HIV by sexual route. One of the most critical is the amount of infectious viral particles present in the transmitting body fluid (e.g. blood, semen or cervicovaginal secretion). Higher concentrations are more likely associated with transmission events. Apparently, in HIV-1, the cutoff of 1500 copies of viral RNA per $\mathrm{ml}$ of plasma is required for efficient transmission [25].

Not surprisingly, plasma and semen viral loads are significantly lower in patients infected with HIV-2 compared to those infected with HIV-1 [26, 27], providing a likely explanation for the reduced transmission rate and spread within human population. This lower viral load is observed throughout the infection and persists until late in the course of the disease, but is remarkably important during asymptomatic stage. During this stage, which in HIV-2 could last for several decades, an undetectable viremia is a hallmark of almost every HIV-2 patients. However, a similar proviral burden is detected in both HIV-1 and HIV-2-infected individuals $[28,29]$. This apparent paradox suggests that the lower plasma viral load observed in HIV-2 infection may be due to lower levels of infectious virus production, or a better host-driven suppression of viral replication, or both.

\subsection{The mucosal barrier}

Besides viral load, numerous barriers decrease the efficiency of mucosal transmission. The foundations of this important notion emanates from studies of couples discordant for HIV-1 infection, which demonstrated that heterosexual transmission is very inefficient requiring multiple exposures for a successful transmission [30, 31]. A detailed understanding of the events surrounding transmission should provide important clues how HIV establishes a new infection and what additional vulnerabilities HIV-2 has, at this stage, that can help explain its lower spread.

Although HIV-1 and HIV-2 (as well as SIV) are commonly referred as "lentivirus" based on the long incubation period and slow onset of disease, it is now clear from data using rhesus macaque model infected with SIV, that initial virus-host interactions, crucial to establishing systemic infection, take place in a rapid succession of related events, soon after mucosal transmission (recently reviewed in [32]). In sexual transmission, the most common form of HIV transmission, these events involve the interactions with cells present in cervical/vaginal mucosa epithelial surfaces. To establish infection, HIV present in semen must go through mucus that covers female genital epithelia and penetrate through the epithelial layer to access 
susceptible cells such as T lymphocytes, macrophages, Langerhans cells and dendritic cells. Mucus, particularly abundant in upper female genital tract, provides the first barrier to HIV infection. Mucus protective role of underlying epithelial cells is provided by the presence of soluble factors (e.g. chemokines produced by epithelial cells) that decrease viral infectivity and by mechanical trapping of virions in the dense protein mesh that constitutes the cervical mucus [33]. By slowing viral diffusion, mucus reduces the probability of infectious virus reach the surface of underlying cells.

Virions that successfully crossed the mucus encounters the epithelial cells layer that line the different compartments of the female genital tract. These different compartments show remarkable differences in the structure of epithelial layer. The mucosa from the lower female genital tract (i.e. exocervix and vagina) consists of stratified squamous epithelium, several layers thick. In contrast, in the upper reproductive compartment (i.e. endocervix and endometrium) the mucosal lining is composed of a single layer of columnar epithelium over the basement membrane and is characterized by the presence of tight junctions between cells.

As expected by their different composition, the lower female genital epithelium is much more robust and provides a more effective physical barrier than the fragile single columnar layer of upper genital epithelium. Furthermore, the junction between the exocervix and the endocervix, where the structure of the epithelium abruptly changes from stratified to single layer (called the transitional or transformational zone), is characterized by an intense immunologic activity and thus enriched with abundant lymphocytes and antigen presenting cells (e.g. dendritic cells and macrophages), particularly during inflammatory processes [34]. The physical vulnerability and the presence of abundant target cells in transitional zone, make this region highly susceptible to HIV entry and infection [35].

Even the thicker vaginal epithelial barrier could quickly expose susceptible cells in the submucosa to HIV. In fact, the stratified squamous epithelium changes markedly through the menstrual cycle, in response to progesterone [36], leading to a thinning of this physical barrier. Additionally, breaches could occur because of microulcerations and breaks in the epithelium due to sexual intercourse, inflammatory processes, sexually transmitted infections, and other genital infections, increasing the likelihood of establishing an HIV infection [37-39].

Additionally, the mere exposure of genital mucosa to semen induces local alterations that could potentiate the transmission of HIV-1 and (probably) HIV-2. These include the neutralization of the acidic $\mathrm{pH}$ of the cervicovaginal secretions, the regulation of inflammatory cytokines in genital tract epithelial cells, and the promotion of leukocyte infiltration and the attraction of Langerhans cells in cervical and vaginal mucosae [40,41]. Semen could also directly promote HIV infection of epithelial target cells through the formation of amyloid fibrils that capture HIV particles and enhances virus-cell attachment and fusion [42]. This amyloidogenic activity of human semen seems to be related with fragments of prostatic acidic phosphatase [42]. Apparently this enhancement is semen donor-dependent but independent of HIV strain or cell type used [43].

In contrast to female genital tract, HIV transmission through male genital tract is poorly understood. Despite the presence of CD4+ T lymphocytes, Langerhans cells, dendritic cells 
and macrophages in the foreskin and glans of the penis [44, 45], the mechanisms underlying the transmission across these mucosae are not completed elucidated. Foreskin seems to play a crucial role in female-to-male transmission of HIV-1, since several randomized controlled clinical trials have shown that circumcision reduce this route of transmission by approximately $60 \%$ [46]. One plausible mechanism for greater susceptibility to HIV-1 infection in uncircumcised men could be the increased risk for sexually transmitted infections and consequent inflammation of the foreskin (reviewed in [47]). This predisposition to local infection and inflammatory reactions will lead to the recruitment of activated target cells that facilitates the early events of HIV transmission and provides a local environment suitable for productive HIV systemic infection.

The vaginal flora could in some circumstances also favour female-to-male HIV transmission. The predominance of potential pathogenic bacteria instead of normal Lactobacillus species, observed during bacterial vaginosis, seems to be related not only with increased risk of HIV-1 acquisition by women (as referred above) but also with higher concentrations of HIV-1 in cervicovaginal secretions, due to a bacterial-driven augmentation of HIV-1 replication and shedding [48-50]. Thus, women with bacterial vaginosis are more infectious and the probability of female-to-male HIV-1 transmission during sexual intercourse is greater than in women with normal vaginal flora [51].

\subsection{Crossing the intact mucosal barrier}

Although infection of mucosal epithelial cells could happen, HIV must gain access to permissive host cells present in underlying submucosa tissue (e.g. dendritic cells macrophages and CD4+ T-lymphocytes) to facilitate virus production and dissemination. The mechanisms for crossing intact stratified squamous epithelium of the vagina or the simple columnar epithelium of the cervix could be one (or more) of the following: (i) transcytosis by a vesicular pathway [52] - an apparently rare but possible event [53]; (ii) capture or infection of dendritic cells resident in the stratified squamous epithelium of the vaginal mucosa and in the underlying tissues of the vagina and cervix [54]; and (iii) direct infection of intraepithelial lymphocytes in the endocervical mucosa [55].

Regardless the pathway used by cell-free HIV virions to penetrate the epithelial cell barrier, they ultimately lead to viral exposure of dendritic cells, macrophages and CD4+ T-lymphocytes present in underlying submucosal tissues, allowing the initiation of infection. Dendritic cells can capture HIV virions through C-type lectin receptors (CLRs) present at cell membrane (e.g. DC-SIGN, DCIR), and internalize the captured virus without being infected. This internalized virus, as well as those bound to dendritic cell membrane, remains full infectious and able to be transmitted to surrounding CD4+ T-lymphocytes through a structure analogous to the immunological synapse, named "virological synapse". This tight adhesive junction between an HIV-exposed dendritic cell and an uninfected CD4+ T-lymphocyte allows the virus to be efficiently transferred from one cell to the other, in a process named trans-infection (for a review in HIV interactions with dendritic cells see [56]). Besides trans-infection through virological synapse, dendritic cells could also transfer HIV to CD4+ T lymphocytes by cell-free exosomes. These endosomal multivesicular bodies (MVB), containing endocytosed HIV particles, could 
be released to extracellular milieu and fuse with target-cell membranes allowing the transfer of HIV to them [57].

Alternatively, HIV can directly infect the dendritic cell subset, present in submucosal tissues (cis-infection), using the natural expression of the main HIV cellular receptors (i.e. CD4 and CCR5; see bellow) at dendritic cell surface $[56,58,59]$. Despite the susceptibility of dendritic cells, conferred by the presence of these major receptors, HIV replication in dendritic cells is in general less productive, compared with CD4+ T lymphocytes [60]. The reasons for the decreased viral production in dendritic cells include: (i) lower expression levels of HIV receptors; (ii) degradation of internalized virions, soon after infection; and (iii) presence of intracellular restriction factors that inhibited post-entry events of replication cycle.

Interestingly, although HIV can infect dendritic cells, extensive viral replication only takes place after dendritic cells come into contact with CD4+ T lymphocytes in lymphoid tissue [61]. The dendritic cell-T lymphocyte interaction provides activation signaling to the latter, allowing HIV to be presented to a population of highly activated and susceptible T-lymphocytes. This further indicates that the infection of dendritic cells by HIV-1 is a double-edged sword: dendritic cells must deliver appropriate signals to T lymphocytes in order to induce an HIVspecific immune response; however, this interaction imposes a close contact between dendritic cells and T lymphocytes (immunological synapse) leaving the latter susceptible to infection by the HIV-1 carried by dendritic cells.

In conclusion, dendritic cell-mediated virus transfer occurs in two distinct phases: in the first phase (trans-infection), dendritic cell capture and internalize virus within endosomal compartments which are relocated at the dendritic cell/CD4+ T-lymphocyte contact zone (virological synapse); alternatively, a fraction of the endocytosed particles may be targeted for exocytosis, associated with exosomes [62]. Both processes occur without dendritic cell productive infection. In the second phase, the direct infection of dendritic cell (cis-infection) contributes to the spread of newly synthesized progeny virus to CD4+ T-lymphocytes [63]. In this regard, several studies have provided important data defining entry-enhancement factors on dendritic cells, such as DC-SIGN, and other C-type lectins receptors (mannose receptor, langerin, syndecan-3, and dendritic cell immunoreceptor - DCIR) [63]. The role of C-type lectin receptors seems to be crucial in both trans- and cis-infection modes. For example, HIV-1 bound to DC-SIGN is rapidly taken up within endolysosomal vacuoles and protected from degradation while remaining infectious for 1-3 days [64]. Interestingly, suppression of DC-SIGN expression has been shown to impair the viral synapse formation, and to inhibit trans-infection of HIV-1 to CD4+ T-lymphocytes [65].

All the data reviewed until now was obtained almost exclusively using HIV-1 model (and in some instances SIV). As referred earlier in this chapter, HIV-2 is a lentivirus that shows a decreased capacity to spread between humans, and probably with additional vulnerabilities during transmission, compared with HIV-1. Besides the lower viral load both in plasma and semen referred previously, little is know about HIV-2 interaction with mucosal cells and how the described physical barriers counteract effective HIV-2 transmission to a new host. For example, very few data exists about HIV-2 interaction with DC-SIGN or the way HIV-2 uses trans-infection mechanisms to spread to T-lymphocytes. Apparently the T-cell line adapted 
strain HIV-2 $2_{\mathrm{ROD}}$ is able to bind to DC-SIGN [66], however data from primary isolates (more closely related to circulating viral variants) are still missing.

Early reports referred that dendritic cells derived from hematopoietic progenitor cells or from peripheral blood monocytes are less susceptible to productive infection by HIV-2 compared with HIV-1 $[67,68]$. Paradoxically, recent data have disclosed a cellular protein (SAMHD1) that inhibits HIV-1 replication in immature monocytes-derived dendritic cells, in dendritic cells derived from PMA-differentiated THP-1 monocytic cell line [69] and in macrophages [70]. This restriction factor affects the efficiency of reverse transcription leading to a reduced amount of viral cDNA [71]. SAMHD1 is counteracted by the HIV-2/SIV Vpx protein and its inhibitory mechanism, in the absence of $\mathrm{Vpx}$, helps to explain the different permissivity of these nondividing cells to lentiviral infection [21]. In this scenario, the non-permissiveness of dendritic cells to HIV-1 infection favours viral dissemination by trans-infection pathway, enabling more virions being delivered to CD4+ T-lymphocytes through virological synapse and eventually enhancing the depletion of these latter cells [72]. More importantly, HIV-2 avoiding the effect of SAMHD1 is more prone to trigger host innate immune responses through type I interferon, mediated by viral DNA-exposed dendritic cells $[73,74]$. Also, productive infection of dendritic cells by HIV-2 may lead to a different spectrum of presented antigens that ultimately could lead to a different adaptive immune response [74].

\section{HIV-2 chronic infection in human host: a natural long-term non progressive infection}

The long-term non-progressive infection that characterizes the HIV-2 infection in humans is determined by several host-virus interactions that, in contrast to HIV-1, enable the control and the confinement of HIV-2 pathogenic potential.

As referred above, the different pathogenic outcome observed in HIV-2 infection compared to HIV-1 seems to be dictated as early as the initial interactions with dendritic cells and macrophages present at mucosae surfaces. The expression of Vpx by HIV-2, allowing the bypass of SAMHD1 restriction and the consequent productive infection of dendritic cells and macrophages (cis-infection), may result in reduced trans-infection to CD4+ T-lymphocytes, a more appropriate innate and adaptive immune response and thus to a more limited infection.

Noteworthy, and despite the described mechanisms that could lead to a hindrance in HIV-2 dissemination at early stages during acute infection, a similar proviral load is observed in HIV-2 and HIV-1 infected patients. These observations suggest that HIV-2, like HIV-1, is able to disseminate and an equal number of target cells are infected during acute and chronic phase or, alternatively, that in HIV-1 a greater number of infected CD4+ T-cells are destroyed in the course of the disease, leading to a similar number of cells containing integrated HIV-1 or HIV-2 genomes.

Typically, infection with HIV-1 is characterized by a gradual and irreversible depletion of CD4+ T-lymphocytes, leading to severe immune dysfunction and the development of AIDS 
within a median time of 10 years. However, in contrast to the aforementioned typical progression, virtually all HIV-2 and a small percentage [75] of HIV-1 infections (appropriately referred as "long-term nonprogressors" or "elite controllers") remain healthy for several decades without any antiretroviral therapy, with undetectable plasma viral load and CD4+ cell counts above 500 cells/ $\mu \mathrm{L}$.

A longer asymptomatic phase and slower progression to AIDS are indeed hallmarks of the natural course of HIV-2 infection [1-3]. A clear demonstration of both features was provided by a prospective study conducted with untreated Senegalese sex workers, where $67 \%$ of HIV-1infected women remain AIDS-free 5 years after seroconversion, in contrast with $100 \%$ for HIV-2-infected women [3]. The rate of developing CD4+ lymphocyte counts bellow 400 cells/ $\mu \mathrm{l}$ was also reduced in HIV-2 participants [3]. Thus, as a rule, HIV-2-infection has no effect on survival in adults [2].

The mechanisms responsible for this less pathogenic course of HIV-2 infection are still poorly understood but surely result from a combination of distinct factors involving the virus, the infected cell and the equilibrium established between viral replication and host immunologic response. This equilibrium is clearly much well preserved in HIV-2 than in HIV-1 infection and it is paradoxical that the study of HIV-2 interaction with host cells remains poorly explored and sometimes neglected. Interestingly, a recent report indicates that a pre-existing infection by HIV-2 appears to inhibit the rate of HIV-1 disease progression [76], together with higher CD4+ T-cell counts and lower viral diversity of HIV-1. This apparent protective effect of HIV-2 may be explained by several viral and immunological mechanisms, namely the higher immunosupression of surface glycoprotein of HIV-2 compared to HIV-1 counterpart [77], or the ability of HIV-2 Nef protein to promote the downmodulation of TCR-CD3 from the surface of CD4+ T-cells [78] and thus the impairment of immunological synapse, established between these lymphocytes and antigen presenting cells (i.e. dendritic cells and macrophages). Both mechanisms have direct impact on immune activation and may help explain the better outcome of HIV-2 infection alone or after superinfection with HIV-1.

\subsection{HIV-2 entry into target cells - Early events}

HIV replication cycle begins by a specific interaction between viral envelope glycoproteins and cellular receptors allowing the binding of virion to target cell. Further sequential interactions eventually lead to viral envelope and cell membrane fusion. The cellular receptors involved in these early events are the CD4 molecule $[79,80]$ and a member of seven-transmembrane, G-protein-coupled, receptors' family (GPCRs), referred as coreceptor. According to the proposed model, the specific binding of SU envelope glycoprotein to CD4 induces structural changes in this glycoprotein that expose, create or stabilize the coreceptor-binding regions, enabling the SU to engage the coreceptor molecule. This second binding event causes further conformational changes in SU that allows the disclosure of an amino-terminal hydrophobic region (fusion peptide) of the TM envelope glycoprotein subunit. The insertion of the fusion peptide in the cell surface leads to the fusion of viral envelope with the cell membrane and the release of viral nucleocapside into the cell cytoplasm (reviewed in [81, 82]). This fusion process as long been assumed to occur at the cell surface through a direct fusion mechanism 
independent of the $\mathrm{pH}$ [83]. However, more recent data describe HIV-1 entry and fusion occurs following endocytosis [84, 85].

After the initial identification of CXCR4 and CCR5 in 1996 [86, 87], several other GPCRs have been described as being able to act as coreceptors for HIV-1, HIV-2 and SIV: CCR1, CCR2b, CCR3, CCR4, CCR5, CCR8, CCR9, CCR10, CXCR2, CXCR4, CXCR5, CXCR6, CX3CR1, XCR1, FPRL1, GPR1, GPR15, APJ, ChemR23, CXCR7/ RDC1, D6, BLTR and US28 [88-92]. Despite this extensive array of potential HIV entry coreceptors, only CCR5 and CXCR4 have been considered important for HIV-1 infection in vivo [93, 94]. This notion stems from studies reporting: (i) the apparent selection of CCR5-using (R5) variants during mucosal transmission; (ii) the predominance of $\mathrm{R} 5$ population during asymptomatic stage of infection; and (iii) the arise and eventual predominance of CXCR4-using (X4) variants in late stages of HIV-1 infection. However, several exceptions to this simplistic R5/X4 dichotomy have been reported [89, 91, 95-104], revealing that some HIV-1 and HIV-2 isolates can exploit other coreceptors in vitro, raising the possibility that these alternate molecules can in vivo contribute to HIV infection of natural target cells, at least under certain circumstances.

Genetic studies of HIV-1 variants present soon after sexual transmission have shown that only R5, and occasionally dual tropic R5X4, are transmitted regardless the diversity of viral population present in initial inoculum. During chronic infection HIV genetic diversity increases due to viral replication based on an error-prone reverse transcriptase. The resulting viral population (or quasiespecies) provides the substrate for natural selection exerted by host immune response and local environment, leading to continuous viral adaptation and persistence within HIV infected patient. However, during mucosal transmission this diversity is severely reduced suggesting a "bottleneck" or "gatekeeper" effect (reviewed in [105]), probably as a result of the biology of mucosal transmission and the kind of cells encountered by HIV (discussed above).

The analysis by single-genome amplification, together with full-length cloning of transmitted/ founder variants, has provided remarkable data on HIV transmission and viral evolution during acute infection. Based on this data, the selection of transmitted/founder viruses encompasses three main signatures: usage of CCR5, high replication rate in CD4+ T-lymphocytes and lack of macrophage tropism (reviewed in [106]). The deficient replication in monocyte-derived macrophages observed in HIV-1 transmitted viruses, although requiring confirmation using tissue macrophages, is consistent with data obtained in nonhuman primates infected with SIV, indicating that CD4+ T-lymphocytes are the predominant cellular substrate for viral replication soon after transmission.

However, a recent and unprecedented observation, regarding HIV coreceptor usage and transmission, revealed that a transmitted/founder HIV-1 was unable to efficiently use either CCR5 or CXCR4 to infect CD4+ cell lines or peripheral blood mononuclear cells [95]. Alternate GPCRs (GPR15, APJ, and FPRL-1) were efficiently used, further emphasizing the notion that "rare" coreceptors could be used in vivo in some circumstances or in some cell populations by HIV-1 and HIV-2 alike. Additionally, Chalmet et al. [107] have recently provided important data showing that the transmitted viruses could be $\mathrm{X} 4$ or R5X4. Considering the established concept, stating that during mucosal transmission the $\mathrm{R} 5$ variants present in initial inoculum 
population of transmitted viruses are favored, these two reports support the idea that non-R5 viruses could indeed be transmitted. This warrants reconsidering the dogma of exclusive R5 variants transmission and should lead us to the following question: is there actually any biological filter at mucosae environment (including physical or chemical barriers, epithelial cells and immune cells present at mucosal surface or in the submucosal layer) that suppresses the invasion and/or dissemination of non-R5 variants; and why in these cases (and other cases?) they were not selected? In other words, are there sufficient and conclusive data to discard the hypothesis of random transmission in favor of a gatekeeper or bottleneck theory [108]? Perhaps the preferential transmission of R5 variants are solely a consequence of their higher proportion in body fluids involved in transmission, either in acute or during most of chronic infection. Further studies are warranted in order to elucidate if X4 or R5X4 variants (and other biotypes, including CCR8-using viruses) are less transmissible.

In HIV-2 no data exists regarding transmitted/founder viruses, or the characteristics or the viral evolution during primary infection. The mechanisms described for HIV-1 and SIV should also be present in HIV-2 infection. However, the identification of HIV-2 isolates unable to infect target cells using the CCR5 or CXCR4 coreceptors [96, 109] obtained from individuals at asymptomatic stage of infection and immunologically competent [96], raises the possibility that, at least in some patients, CCR5 usage is acquired in vivo as a result of HIV-2 evolution from an initial population of CCR5- and CXCR4-independent viruses.

\subsection{Molecular determinants of coreceptor usage}

Identification of the biochemical processes required for HIV fusion and the engagement of chemokine receptors as critical step for HIV entry, has also unveiled several important aspects on envelope glycoproteins structure crucial to the fusion process. HIV-1 and HIV-2 SU glycoprotein contain five conserved regions (C1 to $\mathrm{C} 5$ ), separated by an equal number of variable regions (V1 to V5). The variable regions are limited by cysteine residues forming flexible loops on the outer domain of SU glycoprotein [110-112]. HIV coreceptor usage seems to be largely determined by variable regions of the SU subunit. In HIV-1, the most studied model, the third variable (V3) region has been referred as the major determinant of coreceptor engagement [113-117]. Higher positive net charge (above +5$)$ in V3 region of HIV-1 has been associated with CXCR4 usage (or usage of both CXCR4 and CCR5) [118, 119]. Structural models of SU bound to CD4 and chemokine receptor have provided further information about the functional roles played by several regions of SU, revealing that the V1V2 region is also involved in coreceptor binding, by a direct cooperation with the V3 region [120-124].

In HIV-2, structural and functional studies of the envelope glycoproteins regions are much more scarce and in some aspects contradictory. The genetic characterization of HIV-2 SU has revealed a limited variability, probably as a result of the lower replication rate within the infected individual. Noteworthy, in contrast to HIV-1, the V3 region of HIV-2 SU glycoprotein appears to be highly conserved. Conversely, the V1V2 region is much more prone to genetic variation [125], suggesting that either this region is more exposed and under a stronger selective pressure, or that the lack of V3 loop variation is related to some functional constraints 
that impairs its evolution. Accordingly, the role of HIV-2 V3 region as a target for neutralizing antibodies has been controversial [126-132].

Similar to neutralization data, molecular determinants of coreceptor usage by HIV-2 is also controversial. Some studies had claimed an association between V3 loop sequence and CCR5 or CXCR4 usage [133-137], while others had found no genetic signature underlying coreceptors usage [138-140]. Particularly, the C-terminal region of the V3 loop, a global net charge above +6 and the presence of mutations in amino acids 18 and 19, appear to dictate the ability to use CXCR4 alone or in addition to CCR5 $[134,137]$. However, those studies have some limitations due to the low number of X4 or R5X4 strains and because they restricted the coreceptors usage to the dichotomy R5 vs. X4, without considering the concomitant or alternative use of other coreceptors. We have shown in the molecular characterization of the env gene of two CCR5/ CXCR4-independent isolates that, although this phenotype is determined by the SU glycoprotein [125], no genetic signature could be clearly found in the V3 region of those strains [125]. Noteworthy and considering that the ability to use a certain coreceptor is solely determined by the V3 loop, the absence of a significant variability in this region is hardly concealed with the broad and "exotic" coreceptor usage observed in HIV-2. Obviously, different regions beside V3 cooperate during envelope glycoproteins interaction with cellular receptors, playing a role in coreceptor choice by a particular virus. One of the strongest candidates is the V1V2 region, where an outstanding genetic variability was observed [140], including length variation and loss of potential glycosilation sites. Moreover, some unique sequence signatures were also founded in the central ectodomain and in the second heptad repeat (HR2) of the TM glycoprotein [140]. All these mutations may affect the conformation of the envelope glycoproteins complex, leading to a more open structure. This will affect not only the dynamics of HIV-2 interaction with cellular receptors, but also the way neutralizing epitopes are exposed and recognized by host immune response, leading to decreased viral fitness, lower replication rate and increased susceptibility to neutralization.

\subsection{Evolution of coreceptor usage during HIV-2 chronic infection}

Earlier studies addressing the correlation between HIV infection stages (i.e. acute/primary infection, asymptomatic stage and AIDS) and in vitro biological characteristics of HIV, gave rise to three distinct classifications according to: (i) the efficiency of replication (rapid/high, slow/low); (ii) the capacity to induce syncytia formation in T-cells (syncytium-inducing/non syncytium-inducing; SI/NSI); and (iii) the ability to replicate in primary macrophages vs. Tcell lines (M-tropic/T-tropic). From these earlier studies it was also clear that, during the course of infection, selection might occur for variants more cytopathic (i.e. able to induce syncytia), with faster replication kinetics (rapid/high) and with tropism for T-cell lines (T-tropic).

Identification of the biochemical processes required for HIV fusion and the engagement of chemokine receptors, clarified the determinants of HIV tropism. Consistent with the proposed model, HIV cell tropism is largely determined by the expression patterns of the appropriate coreceptor molecule at the target-cell membrane. T-tropic viruses (in general with rapid/high and SI phenotype) required the presence of CXCR4 coreceptor (X4 strains) while M-tropic (associated generally with slow/low and NSI phenotype) use CCR5 as coreceptor (R5 strains). 
The evolution that was observed in viral phenotype has now an explanation based on the coreceptors used: isolates obtained during asymptomatic stage are R5 (formerly NSI, M-tropic and slow/low) while in later stages of infection, coincident with immunodeficiency and opportunistic infections, the predominant variants are X4 (formerly SI, T-tropic and rapid/ high). This shift from predominance of $\mathrm{R} 5$ variants to $\mathrm{X} 4$, during disease progression, occurs in about $40 \%$ of the patients and could be seen as an additional consequence of an already deteriorated immune response, which contributes to an accelerated depletion of T-lymphocytes and disease progression.

In HIV-2, the usage of cell receptors seems to be much more complex and the correlation between disease stage and receptors usage is apparently less clear-cut than in HIV-1. The key notions about cell receptors engagement by HIV-2 are: (i) non-usage of CCR5 or CXCR4 as coreceptors; (ii) a broader coreceptor usage compared to HIV-1; and (iii) the CD4-independent infection of target cells.

\subsubsection{Non-usage of CCR5 or CXCR4 as coreceptors}

Although CCR5 or CXCR4 usage seems to be an absolute requirement for HIV to fuse its envelope with target-cell membrane, we and others have identified HIV-2 variants that in vitro do not use those chemokine receptors (or use it inefficiently) as cofactors for viral entry. These reports indicate that other coreceptors could replace CCR5 and CXCR4 as key players in HIV infection, not just "in addition to" but also "instead of" these coreceptors, clearly suggesting that they have an important role in HIV-2 infection and pathogenesis. Furthermore, we demonstrated that these variants have lower replicative capacity in vitro [96, 125], an observation later confirmed by others [141].

The main inference made from studies addressing coreceptors usage by HIV is that the acquisition of CCR5 usage is crucial for HIV pathogenesis. And why CCR5 usage is so important and provides a clear selective advantage in vivo? One of the reasons is because CCR5 usage confers HIV the ability to infect stimulated, full-permissive cells, leading to the production of a significantly more infectious viral population. While CXCR4 is expressed in both resting and stimulated T-lymphocytes [142], CCR5 expression is higher in memory CD4+ Tcells (CD45RO+) than in naïve (non-activated) CD4+ T-lymphocyte subset (CD45RA+) [143, 144]. Remarkably, the former are highly permissive to HIV replication, while productive infection of CD45RA+ lymphocytes requires cellular activation soon after viral entry; otherwise, an abortive infection is observed [145].

In addition, the persistence of R5 viruses throughout the asymptomatic stage and in some cases even in individuals with clinical symptoms, suggests that they may escape immune surveillance mechanisms (e.g. neutralization by specific antibodies) or that they could infect longlived cell reservoirs, such as macrophages and dendritic cells, thus providing long-lasting R5 viruses production.

Interestingly, the described CCR5/CXCR4-independent HIV-2 variants were obtained during asymptomatic stage of infection [96, 109]. As referred, HIV-1 and HIV-2 infections are strikingly different during this period: a longer asymptomatic period with higher CD4+ T-cell 
counts and undetectable viremia is observed in HIV-2. The host and viral factors that contributes for this high level of control remain poorly understood, but we hypothesized that one of the viral factors that could be involved is the existence of a less fitted viral population, during a variable period of the asymptomatic stage. This population has lower replicative capacity and, at least in some cases, they do not efficiently use CCR5 and/or CXCR4 coreceptors.

\subsubsection{Broad coreceptor usage}

A hallmark of earlier studies addressing the coreceptors usage by HIV-2 primary isolates was that HIV-2 entry into target cells could be mediated by an array of different GPCRs in vitro (reviewed in [146, 147]). In contrast, HIV-1 isolates with coreceptor usage biotype other than R5 and/or X4 have been rarely described. Furthermore, HIV-2 isolates can exploit these alternative coreceptors as efficiently as they use CCR5 or CXCR4, even those rarely used by HIV-1. However, it should be noted that most of the viruses used in these studies were obtained from patients in advanced disease stages, were more pathogenic variants could be present, presumably leading to a bias in the viral population that was preferentially isolated.

The ability to use a larger set of coreceptors should constitute an advantage for HIV-2, since it contributes to a potentially broader cell tropism, with the inherent ability to infect different cell types in different compartments [98, 135, 148]. Yet, as referred in R5-to-X4 evolution (see above) this could lead to the infection of non-activated cells, and thus to abortive cycles. Moreover, the engagement of alternative GPCRs, although being sufficient to mediate HIV-2 entry, could be inadequate to trigger appropriate intracellular signaling required for productive infection. Several studies have shown a direct correlation between the capacity of envelope glycoproteins to elicit appropriate signaling and the ability to perform a productive infection in several cell types (reviewed in [149]). Such signalling events affect multiple intracellular pathways (in a process mimicking chemokine signaling through binding to their receptors) and include: actin depolymerization, cytoskeleton rearrangement, migration of cells and activation of kinases and transcription factors associated with cell activation (Table 2). Although the relevance of coreceptor signaling in HIV pathogenesis has not been clearly defined, it seems that HIV takes advantage of the chemokine signaling network to create an intracellular environment suitable to accomplish a productive infection [149].

Another factor that may account for the apparent paradox of HIV-2 broad coreceptor usage and low virus production in vivo, could be the relative concentration of appropriate viral receptors and their co-localization in plasma membrane of specific cell types [150-153]. Moreover, their expression levels could change during activation/differentiation of T lymphocytes and macrophages, as referred for CD4, CCR5 and CXCR4 [144, 154, 155]. Thus, the availability of target cells expressing CD4 and the appropriate coreceptor in vivo could be a limiting factor for HIV-2 infection and spread.

Recently we have studied the contribution of CCR8 as an effective coreceptor for HIV-1 and HIV-2 primary isolates [89]. A major and interesting finding arise from this report: a minor coreceptor such as CCR8 was used much more frequently by HIV-1 than by HIV-2 primary isolates, regardless the clinical stage, the plasma viral load or the CD4+ T-cell counts of patients. The rationale for revisiting CCR8 as coreceptor was based on our earlier findings, revealing 
the existence of HIV-2 unable to use CCR5 or CXCR4 as coreceptors to infect primary CD4+ lymphocytes or CD4-expressing cell lines [96, 125]. CCR8, formerly known as TER1, ChemR1 and CKR-L1, is the receptor for the chemokine CCL1/I-309 [156, 157]. It is expressed in a wide range of cells; some of them are primary targets for HIV infection in vivo, e.g. monocytes, thymocytes and peripheral blood CD4+ T-lymphocytes [157-159]. Its tissue distribution and the significant proportion of HIV-1 isolates able to use CCR8, deserves a deeper discussion. If in HIV-2, due to the well-known promiscuous usage of chemokine receptors as coreceptors, the usage of this GPCR was expected, in HIV-1, this was completely unpredicted. As I pointed before, identification of viruses able to use other coreceptors besides CCR5 and CXCR4 seems to be an abnormality in HIV-1. Yet, the findings presented in the cited report [89] together with previous data [91, 100, 103, 160], indicating the efficient use of CCR8 as coreceptor by distinct HIV-1 isolates, either in indicator cell lines or in primary cells, highlight the potential relevance of this molecule for viral transmission and pathogenesis, including HIV-1.

\begin{tabular}{|c|c|c|c|}
\hline \multicolumn{2}{|c|}{$\begin{array}{l}\text { Chemokine interaction with } C X C R 4^{*} \text { or CCR5 ** } \\
\text { receptors }\end{array}$} & \multicolumn{2}{|c|}{ HIV interaction *** with CCR5 or CXCR4 coreceptors } \\
\hline Primary activation & Downstream outcome & Primary activation & Downstream outcome \\
\hline $\begin{array}{l}\text { Activation of } \\
\text { phospholipase } C-\gamma\end{array}$ & $\begin{array}{l}\text { Transcriptional activation. } \\
\text { Cell migration (chemotaxis) }\end{array}$ & $\begin{array}{l}\text { Activation of } \\
\text { phospholipase } C-\gamma\end{array}$ & $\begin{array}{l}\text { Transcriptional activation. } \\
\text { Cell migration }\end{array}$ \\
\hline $\begin{array}{l}\text { Activation of lipid } \\
\text { kinase PI3K }\end{array}$ & $\begin{array}{l}\text { Transcriptional activation. } \\
\text { Cell adhesion. } \\
\text { Cell survival }\end{array}$ & $\begin{array}{l}\text { Activation of lipid } \\
\text { kinase PI3K }\end{array}$ & $\begin{array}{l}\text { Cell adhesion. } \\
\text { Cell survival }\end{array}$ \\
\hline $\begin{array}{l}\text { Activation of guanine } \\
\text { nucleotide exchange } \\
\text { factors specific for Rho } \\
\text { family GTPases }\end{array}$ & $\begin{array}{l}\text { Modulation of cytoskeleton: } \\
\text { actin rearrangement; myosin } \\
\text { light-chain phosphorilation and } \\
\text { microtubule rearrangement }\end{array}$ & $\begin{array}{l}\text { Activation of guanine } \\
\text { nucleotide exchange } \\
\text { factors specific for Rho } \\
\text { family GTPases }\end{array}$ & $\begin{array}{l}\text { Modulation of cytoskeleton: } \\
\text { actin rearrangement }\end{array}$ \\
\hline
\end{tabular}

Table 2. Major chemokine receptor signalling pathways triggered after binding of chemokines or HIV envelope surface glycoprotein (for more details see [149])

It is widely recognized that during later stages of HIV-1 infection, a significant proportion of viral variants that constitute the quasispecies within an infected individual, evolve in order to efficiently use CXCR4 (and probably other chemokine receptors) in addition to, or instead of, CCR5-using variants, which predominate during early stages of infection [161]. These X4 variants are characterized by increased replicative capacity, a more cytopathic phenotype and the ability to infect a broader range of cells [162]. Accordingly, the emergence of X4 variants is associated with accelerated disease progression and increased CD4+ T-lymphocytes depletion [161]. The infection of naive T-cells by X4 strains is likely to occur early in Tlymphocyte ontogeny and may thus contribute to the described enhancement of T-cells depletion by X4 strains. Studies of thymocyte development demonstrated that CXCR4 is highly expressed on immature T-cell progenitors resident to thymic cortex. As a result, infection of 
immature thymocytes by X4 strains may disrupt thymopoiesis leading to an impairment of Tcell development and to an accelerated T-cell depletion [163-165].

However, in HIV-2 the correlation between disease progression and coreceptor usage was not consistently observed and a clear pattern of R5-to-X4 evolution, along with disease progression, has been difficult to establish. Even so, R5 viruses are mainly observed in asymptomatic or early symptomatic patients, and strains showing a restricted CXCR4 usage are only observed in late symptomatic individuals [96, 166-168]. In a study comparing CCR5, CXCR4 and CCR8 usage by HIV-1 and HIV-2, an interesting observation was withdrawn pointing to a more frequent usage of CXCR4 by HIV-1 than by HIV-2 primary isolates [89]. Conversely, CCR5 use was significantly more common in HIV-2 isolates than in HIV-1. According to the described enhancement of T-cell depletion by $\mathrm{X} 4$ variants, the predominance of a non- $\mathrm{X} 4$ viral population, mostly observed in HIV-2 cohort, may contribute to better preserve CD4+ lymphocyte repertoire and immune system functionality and help explain the slower disease progression, generally observed in HIV-2 infected patients compared with HIV-1.

\subsubsection{CD4-independent infection}

Despite the potential advantage of broader cell tropism associated with lower CD4 dependency, CD4-independent HIV-1 variants, although readily derived in vitro [169-172], have been rarely described in vivo [173-175]. In contrast, several primary HIV-2 and SIV isolates have been shown to enter cells in a CD4-independent way [81, 148, 168, 176-179].

The ability to entry cells through direct interaction with the coreceptor molecule, bypassing the requirement of prior $\mathrm{CD} 4$ engagement, may enable viruses to infect a broader range of cells CD4 negative/coreceptor positive, or cells where CD4 expression is lower and thus limiting. This notion is consistent with studies showing that neutopathogenic HIV-1 variants show reduced CD4 dependence and the ability to infect CD4-negative cells. Viruses with a CD4independent phenotype could infect cells in different tissue compartments within an infected individual, besides haematopoietic CD4+ cells, such as the brain, testes, lymphoid tissue, kidneys or lungs, further suggesting that CD4-independence could constitute an advantage and might play an important role in some particular tissue settings [148, 173-175, 180, 181]. Interestingly, the CD4-independent phenotype not only appears to be a potential advantage but it can be easily acquired as a consequence of very few amino acids changes in viral envelope glycoproteins [169-172, 182, 183]. Therefore, a central question may arise: why CD4-independent HIV-1 variants are so rare, or why the occurrence of such variants in HIV-2 is not associated with an increased pathogenic outcome?

The infrequent detection of CD4-independent HIV-1 isolates should reflect the selective advantage of CD4 interaction prior to coreceptor engagement. One of the reasons could be the high affinity of CD4-SU envelope glycoprotein binding, stabilizing virion attachment to target cell. However, many other surface molecules have been described to interact with HIV-1 (reviewed in [184]) and thus capable of mediate a stabilizing interaction with virions. Another possible explanation for CD4 dependency could be the shielding of coreceptor binding sites from neutralizing antibodies [170, 182, 185-189]. Considering the proposed mechanism for HIV fusion, the CD4-independent infection imposes that the coreceptor-binding site is already 
formed or exposed allowing the virus to circumvent the need for prior CD4 interaction. The conformation of envelope glycoproteins allowing the direct interaction with coreceptor (as well as the interaction with different coreceptors) might elicit neutralizing antibodies targeting these critical regions, favoring the host immunological control in HIV-2 infection. Consistent with this notion, sera from HIV-2 infected individuals have higher and broader neutralizing capacity compared to those of HIV-1 [126, 190].

Studies conducted with HIV-2 CD4-independent strains clearly demonstrated a less fitted interaction and a reduced replication rate in vitro. This suggests that the coreceptor-binding site is only partially formed (or exposed) affecting the stability/affinity of the complex formed between coreceptor and the envelope glycoproteins. In turn, this may also indicate that prior CD4 interaction is important to assure the infection of more permissive cells, enabling a more productive infection. The intracellular factors that dictate this "friendly" environment for viral replication in CD4+ cells remain unknown but may be related to some unidentified restriction factors that could be present in CD4 negative cells. Conversely, the interaction with CD4 may induce cell-signaling events that could account for optimal viral replication conditions, as I discussed earlier about coreceptor engagement by envelope glycoproteins.

\section{Concluding remarks}

Two lentiviruses infect humans with different outcomes. HIV-1 and HIV-2, both a result of cross-species transmission, have similar genomic and structural characteristics, and yet they distinctively affect human host. While HIV-1 infection leads to severe immune dysfunction and the development of AIDS within a median time of 10 years, HIV-2 usually takes decades to accomplish that.

Through this chapter, I have provided several data that help to explain this different pathogenic potential of HIV-1 and HIV-2 (see Table 3 for a brief summary). I have focused on those viral characteristics that determines different virus-host interactions and outcomes:

- Lower viral load in body fluids directly involved in HIV-2 transmission.

- Avoidance of SAMHD1 degradation of viral cDNA during infection of dendritic cells, leading to sensing and stronger innate immune response by HIV-2.

- Inability to use CCR5 or CXCR4 that severely affects viral fitness during asymptomatic phase of infection.

- A less common acquisition of CXCR4 usage during the course of infection and the consequent maintenance of a predominant less cytopathic R5 population, which may help to better preserve CD4+ lymphocyte repertoire and immune system functionality in HIV-2 infected individuals.

- Usage of alternate coreceptors that ultimately could lead to inappropriate cell signalling and/or infection of cell populations unable to fully support the HIV-2 replication cycle. 
- CD4-independent infection of target cells, providing the potential to infect cells in different compartments but also exposing critical regions of coreceptor binding site to host neutralizing immune response.

- A more relaxed envelope glycoproteins structure that could modulate HIV-2 interaction with cellular receptors, helping explaining the exotic coreceptor usage and CD4-independency but also a less fitted interaction with those receptors and thus to an inappropriate cell signalling.

Much more data is needed to fully comprehend the way human host is able to cope with HIV-2 but not with HIV-1 infection. Further studies addressing HIV-2-cell interactions are warranted as they could reveal undisclosed mechanisms and pathways that may help to clarify the underlying causes for the different pathogenic potential observed between HIV-2 and HIV-1, en route to assist in HIV vaccine development and new therapeutic strategies.

\begin{tabular}{lll}
\hline & HIV-1 & HIV-2 \\
\hline $\begin{array}{ll}\text { Infection of dendritic } \\
\text { cells }\end{array}$ & $\begin{array}{l}\text { Conflicting results. Susceptible to antiviral } \\
\text { activity of cellular factor SAMHD1 }\end{array}$ & $\begin{array}{l}\text { Conflicting results. Resistant to antiviral } \\
\text { activity of cellular factor SAMHD1 (by Vpx } \\
\text { protein) }\end{array}$ \\
\hline $\begin{array}{l}\text { Innate immune } \\
\text { response }\end{array}$ & $\begin{array}{l}\text { Less efficiently triggered due to several } \\
\text { factors, namely to the restricted infection } \\
\text { of dendritic cells }\end{array}$ & $\begin{array}{l}\text { More robust than in HIV-1 namely } \\
\text { because infection of dendritic cells could } \\
\text { trigger IFN-I mediated response }\end{array}$ \\
\hline $\begin{array}{l}\text { Coreceptor usage } \\
\text { CD4-independent }\end{array}$ & $\begin{array}{l}\text { Generally described has only being able to } \\
\text { efficiently use CCR5 and CXCR4 }\end{array}$ & $\begin{array}{l}\text { Generally described has being able to } \\
\text { efficiently use other coreceptors besides } \\
\text { CCR5 and CXCR4 }\end{array}$ \\
\hline $\begin{array}{l}\text { Molecular } \\
\text { determinants of } \\
\text { coreceptor usage }\end{array}$ & $\begin{array}{l}\text { Mostly the V3 region of SU envelope } \\
\text { glycoprotein }\end{array}$ & $\begin{array}{l}\text { Several primary isolates reported } \\
\text { of serum antibodies }\end{array}$ \\
\hline
\end{tabular}

Table 3. Differences between HIV-1 and HIV-2 regarding virus-host interaction (see text for further details)

\section{Acknowledgements}

The author wish to acknowledge bioMérieux Portugal for the financial support in the article processing charge of this chapter. 


\section{Author details}

José Miguel Azevedo-Pereira

Molecular Pathogenesis Centre, Retrovirus and Related Infections Unit (CPM-URIA), Faculty of Pharmacy, University of Lisbon (FFUL), Lisbon, Portugal

\section{References}

[1] Whittle, H, Morris, J, Todd, J, Corrah, T, Sabally, S, Bangali, J, et al. HIV-2-infected patients survive longer than HIV-1-infected patients. AIDS. (1994). , 8(11), 1617-1620.

[2] Poulsen, A. G, Aaby, P, Larsen, O, Jensen, H, Naucler, A, Lisse, I. M, et al. year HIV-2-associated mortality in an urban community in Bissau, west Africa. Lancet. (1997). , 349(9056), 911-914.

[3] Marlink, R, Kanki, P, Thior, I, Travers, K, Eisen, G, Siby, T, et al. Reduced rate of disease development after HIV-2 infection as compared to HIV-1. Science. (1994). , 265(5178), 1587-1590.

[4] Virus Taxonomy: (2009). Release [database on the Internet]International Comittee on Taxonomy of Viruses (ICTV). [cited 19 June 2012]. Available from: http://ictvonline.org/virusTaxonomy.asp?version=2009\&bhcp=1.

[5] Clavel, F, Guetard, D, Brun-vezinet, F, Chamaret, S, Rey, M. A, Santos-ferreira, M. O, et al. Isolation of a new human retrovirus from West African patients with AIDS. Science. (1986). , 233(4761), 343-346.

[6] Clavel, F, Mansinho, K, Chamaret, S, Guetard, D, Favier, V, Nina, J, et al. Human immunodeficiency virus type 2 infection associated with AIDS in West Africa. New England Journal of Medicine. (1987). , 316(19), 1180-1185.

[7] Keele, B. F, Van Heuverswyn, F, Li, Y, Bailes, E, Takehisa, J, Santiago, M. L, et al. Chimpanzee reservoirs of pandemic and nonpandemic HIV-1. Science. (2006). , 313(5786), 523-526.

[8] Lemey, P, Pybus, O. G, Wang, B, Saksena, N. K, Salemi, M, \& Vandamme, A. M. Tracing the origin and history of the HIV-2 epidemic. Proceedings of the National Academy of Sciences of the United States of America. (2003). , 100(11), 6588-6592.

[9] Hahn, B. H, Shaw, G. M, De Cock, K. M, \& Sharp, P. M. AIDS as a zoonosis: scientific and public health implications. Science. (2000). , 287(5453), 607-614.

[10] Korber, B, Muldoon, M, Theiler, J, Gao, F, Gupta, R, Lapedes, A, et al. Timing the ancestor of the HIV-1 pandemic strains. Science. (2000). , 288(5472), 1789-1796. 
[11] Sharp, P. M, \& Hahn, B. H. The evolution of HIV-1 and the origin of AIDS. Philosophical Transactions of the Royal Society of London Series B, Biological sciences. (2010). , 365(1552), 2487-2494.

[12] Suzuki, Y, \& Craigie, R. The road to chromatin- nuclear entry of retroviruses. Nature Reviews Microbiology. (2007). , 5(3), 187-196.

[13] Frankel, A. D, \& Young, J. A. HIV-1: fifteen proteins and an RNA. Annual Review of Biochemistry. (1998). , 67-1.

[14] Schubert, U, Anton, L. C, Bacik, I, Cox, J. H, Bour, S, Bennink, J. R, et al. CD4 glycoprotein degradation induced by human immunodeficiency virus type $1 \mathrm{Vpu}$ protein requires the function of proteasomes and the ubiquitin-conjugating pathway. Journal of Virology. (1998). , 72(3), 2280-2288.

[15] Varthakavi, V, Smith, R. M, Bour, S. P, Strebel, K, \& Spearman, P. Viral protein U counteracts a human host cell restriction that inhibits HIV-1 particle production. Proceedings of the National Academy of Sciences of the United States of America. (2003). , 100(25), 15154-15159.

[16] Perez-caballero, D, Zang, T, Ebrahimi, A, Mcnatt, M. W, Gregory, D. A, Johnson, M. C, et al. Tetherin inhibits HIV-1 release by directly tethering virions to cells. Cell. (2009). , 139(3), 499-511.

[17] Neil, S. J, Zang, T, \& Bieniasz, P. D. Tetherin inhibits retrovirus release and is antagonized by HIV-1 Vpu. Nature. (2008). , 451(7177), 425-430.

[18] Abada, P, Noble, B, \& Cannon, P. M. Functional domains within the human immunodeficiency virus type 2 envelope protein required to enhance virus production. Journal of Virology. (2005). , 79(6), 3627-3638.

[19] Bour, S. P, Schubert, U, Peden, K, \& Strebel, K. The envelope glycoprotein of human immunodeficiency virus type 2 enhances viral particle release: a Vpu-like factor? Journal of Virology. (1996). , 70(2), 820-829.

[20] Andersen, J. L, \& Planelles, V. The role of Vpr in HIV-1 pathogenesis. Current HIV Research. (2005). , 3(1), 43-51.

[21] Goujon, C, Rivière, L, Jarrosson-wuilleme, L, Bernaud, J, Rigal, D, Darlix, J-L, et al. SIVSM/HIV-2 Vpx proteins promote retroviral escape from a proteasome-dependent restriction pathway present in human dendritic cells. Retrovirology. (2007).

[22] Kanki, P, Boup, M, Marlink, S, Travers, R, Hsieh, K, \& Gueye, C. C. A, et al. Prevalence and risk determinants of human immunodeficiency virus type 2 (HIV-2) and human immunodeficiency virus type 1 (HIV-1) in west African female prostitutes. American Journal of Epidemiology. (1992). , 136(7), 895-907.

[23] Burgard, M, Jasseron, C, Matheron, S, Damond, F, Hamrene, K, Blanche, S, et al. Mother-to-child transmission of HIV-2 infection from 1986 to 2007 in the ANRS 
French Perinatal Cohort EPF-CO1. Clinical Infectious Diseases. (2010). , 51(7), 833-843.

[24] Van Tienen, C, Van Der Loeff, M. S, Zaman, S. M, Vincent, T, Sarge-njie, R, Peterson, I, et al. Two Distinct Epidemics: The Rise of HIV-1 and Decline of HIV-2 Infection Between 1990 and 2007 in Rural Guinea-Bissau. Journal of Acquired Immune Deficiency Syndromes. (2009). , 53(5), 640-647.

[25] Quinn, T. C, Wawer, M. J, Sewankambo, N, Serwadda, D, Li, C, Wabwire-mangen, F, et al. Viral load and heterosexual transmission of human immunodeficiency virus type 1. Rakai Project Study Group. New England Journal of Medicine. (2000). , 342(13), 921-929.

[26] Gottlieb, G. S, Hawes, S. E, Agne, H. D, Stern, J. E, Critchlow, C. W, Kiviat, N. B, et al. Lower levels of HIV RNA in semen in HIV-2 compared with HIV-1 infection: implications for differences in transmission. AIDS. (2006). , 20(6), 895-900.

[27] Popper, S. J, Sarr, A. D, Travers, K. U, Gueye-ndiaye, A, Mboup, S, Essex, M. E, et al. Lower human immunodeficiency virus (HIV) type 2 viral load reflects the difference in pathogenicity of HIV-1 and HIV-2. Journal of Infectious Diseases. (1999). , 180(4), 1116-1121.

[28] Gomes, P, Taveira, N. C, Pereira, J. M, Antunes, F, Ferreira, M. O, \& Lourenco, M. H. Quantitation of human immunodeficiency virus type 2 DNA in peripheral blood mononuclear cells by using a quantitative-competitive PCR assay. Journal of Clinical Microbiology. (1999). , 37(2), 453-456.

[29] Popper, S. J, Sarr, A. D, Gueye-ndiaye, A, Mboup, S, Essex, M. E, \& Kanki, P. J. Low plasma human immunodeficiency virus type 2 viral load is independent of proviral load: low virus production in vivo. Journal of Virology. (2000). , 74(3), 1554-1557.

[30] Wawer, M. J, Gray, R. H, Sewankambo, N. K, Serwadda, D, Li, X, Laeyendecker, O, et al. Rates of HIV-1 transmission per coital act, by stage of HIV-1 infection, in Rakai, Uganda. Journal of Infectious Diseases. (2005). , 191(9), 1403-1409.

[31] Gray, R. H, Wawer, M. J, Brookmeyer, R, Sewankambo, N. K, Serwadda, D, Wabwire-mangen, F, et al. Probability of HIV-1 transmission per coital act in monogamous, heterosexual, HIV-1-discordant couples in Rakai, Uganda. Lancet. (2001). , 357(9263), 1149-1153.

[32] Haase, A. T. Early events in sexual transmission of HIV and SIV and opportunities for interventions. Annual Review of Medicine. (2011). , 62-127.

[33] Lai, S. K, Hida, K, Shukair, S, Wang, Y. Y, Figueiredo, A, Cone, R, et al. Human immunodeficiency virus type 1 is trapped by acidic but not by neutralized human cervicovaginal mucus. Journal of Virology. (2009). , 83(21), 11196-11200. 
[34] Pudney, J, Quayle, A. J, \& Anderson, D. J. Immunological microenvironments in the human vagina and cervix: mediators of cellular immunity are concentrated in the cervical transformation zone. Biology of Reproduction. (2005). , 73(6), 1253-1263.

[35] Moss, G. B, Clemetson, D, Costa, D, Plummer, L, Ndinya-achola, F. A, \& Reilly, J. O. $\mathrm{M}$, et al. Association of cervical ectopy with heterosexual transmission of human immunodeficiency virus: results of a study of couples in Nairobi, Kenya. Journal of Infectious Diseases. (1991). , 164(3), 588-591.

[36] Marx, P. A, Spira, A. I, Gettie, A, Dailey, P. J, Veazey, R. S, Lackner, A. A, et al. Progesterone implants enhance SIV vaginal transmission and early virus load. Nature Medicine. (1996). , 2(10), 1084-1089.

[37] Norvell, M. K, Benrubi, G. I, \& Thompson, R. J. Investigation of microtrauma after sexual intercourse. Journal of Reproductive Medicine. (1984). , 29(4), 269-271.

[38] Sewankambo, N, Gray, R. H, Wawer, M. J, Paxton, L, Mcnaim, D, Wabwire-mangen, F, et al. HIV-1 infection associated with abnormal vaginal flora morphology and bacterial vaginosis. Lancet. (1997). , 350(9077), 546-550.

[39] Cohn, M. A, Frankel, S. S, Rugpao, S, Young, M. A, Willett, G, Tovanabutra, S, et al. Chronic inflammation with increased human immunodeficiency virus (HIV) RNA expression in the vaginal epithelium of HIV-infected Thai women. Journal of Infectious Diseases. (2001). , 184(4), 410-417.

[40] Sharkey, D. J, Macpherson, A. M, Tremellen, K. P, \& Robertson, S. A. Seminal plasma differentially regulates inflammatory cytokine gene expression in human cervical and vaginal epithelial cells. Molecular Human Reproduction. (2007). , 13(7), 491-501.

[41] Berlier, W, Cremel, M, Hamzeh, H, Levy, R, Lucht, F, Bourlet, T, et al. Seminal plasma promotes the attraction of Langerhans cells via the secretion of CCL20 by vaginal epithelial cells: involvement in the sexual transmission of HIV. Human Reproduction. (2006). , 21(5), 1135-1142.

[42] Münch, J, Rücker, E, Ständker, L, Adermann, K, Goffinet, C, Schindler, M, et al. Semen-derived amyloid fibrils drastically enhance HIV infection. Cell. (2007). , 131(6), 1059-1071.

[43] Kim, K-A, Yolamanova, M, Zirafi, O, Roan, N. R, Staendker, L, Forssmann, W-G, et al. Semen-mediated enhancement of HIV infection is donor-dependent and correlates with the levels of SEVI. Retrovirology. (2010).

[44] Mccoombe, S. G, \& Short, R. V. Potential HIV-1 target cells in the human penis. AIDS. (2006). , 20(11), 1491-1495.

[45] Patterson, B. K, Landay, A, Siegel, J. N, Flener, Z, Pessis, D, Chaviano, A, et al. Susceptibility to human immunodeficiency virus-1 infection of human foreskin and cervical tissue grown in explant culture. American Journal of Pathology. (2002). , 161(3), 867-873. 
[46] Auvert, B, Taljaard, D, Lagarde, E, Sobngwi-tambekou, J, Sitta, R, \& Puren, A. Randomized, controlled intervention trial of male circumcision for reduction of HIV infection risk: the ANRS 1265 Trial. PLoS Medicine. (2005). e298.

[47] Edwards, S. Balanitis and balanoposthitis: a review. Genitourinary Medicine. (1996). , 72(3), 155-159.

[48] Sha, B. E, Zariffard, M. R, Wang, Q. J, Chen, H. Y, Bremer, J, Cohen, M. H, et al. Female genital-tract HIV load correlates inversely with Lactobacillus species but positively with bacterial vaginosis and Mycoplasma hominis. Journal of Infectious Diseases. (2005). , 191(1), 25-32.

[49] Hashemi, F. B, Ghassemi, M, Faro, S, Aroutcheva, A, \& Spear, G. T. Induction of human immunodeficiency virus type 1 expression by anaerobes associated with bacterial vaginosis. Journal of Infectious Diseases. (2000). , 181(5), 1574-1580.

[50] Simoes, J. A, Hashemi, F. B, Aroutcheva, A. A, Heimler, I, Spear, G. T, Shott, S, et al. Human immunodeficiency virus type 1 stimulatory activity by Gardnerella vaginalis: relationship to biotypes and other pathogenic characteristics. Journal of Infectious Diseases. (2001). , 184(1), 22-27.

[51] Cohen, C. R, Lingappa, J. R, Baeten, J. M, Ngayo, M. O, Spiegel, C. A, Hong, T, et al. Bacterial Vaginosis Associated with Increased Risk of Female-to-Male HIV-1 Transmission: A Prospective Cohort Analysis among African Couples. PLoS Medicine. (2012). e1001251.

[52] Bomsel, M. Transcytosis of infectious human immunodeficiency virus across a tight human epithelial cell line barrier. Nature Medicine. (1997). , 3(1), 42-47.

[53] Bobardt, M. D, Chatterji, U, Selvarajah, S, Van Der Schueren, B, David, G, Kahn, B, et al. Cell-free human immunodeficiency virus type 1 transcytosis through primary genital epithelial cells. Journal of Virology. (2007). , 81(1), 395-405.

[54] Frank, I, \& Pope, M. The enigma of dendritic cell-immunodeficiency virus interplay. Current Molecular Medicine. (2002). , 2(3), 229-248.

[55] Zhang, Z, Schuler, T, Zupancic, M, Wietgrefe, S, Staskus, K. A, Reimann, K. A, et al. Sexual transmission and propagation of SIV and HIV in resting and activated CD4+ T cells. Science. (1999). , 286(5443), 1353-1357.

[56] $\mathrm{Wu}, \mathrm{L}$. KewalRamani VN. Dendritic-cell interactions with HIV: infection and viral dissemination. Nature Reviews Immunology. (2006). , 6(11), 859-868.

[57] Wiley, R. D, \& Gummuluru, S. Immature dendritic cell-derived exosomes can mediate HIV-1 trans infection. Proceedings of the National Academy of Sciences of the United States of America. (2006). , 103(3), 738-743. 
[58] Rubbert, A, Combadiere, C, Ostrowski, M, Arthos, J, Dybul, M, Machado, E, et al. Dendritic cells express multiple chemokine receptors used as coreceptors for HIV entry. Journal of Immunology. (1998). , 160(8), 3933-3941.

[59] Granelli-piperno, A, Moser, B, Pope, M, Chen, D, Wei, Y, Isdell, F, et al. Efficient interaction of HIV-1 with purified dendritic cells via multiple chemokine coreceptors. Journal of Experimental Medicine. (1996). , 184(6), 2433-2438.

[60] Canque, B, Bakri, Y, Camus, S, Yagello, M, Benjouad, A, \& Gluckman, J. C. The susceptibility to X4 and R5 human immunodeficiency virus-1 strains of dendritic cells derived in vitro from CD34(+) hematopoietic progenitor cells is primarily determined by their maturation stage. Blood. (1999). , 93(11), 3866-3875.

[61] Granelli-piperno, A, Finkel, V, Delgado, E, \& Steinman, R. M. Virus replication begins in dendritic cells during the transmission of HIV-1 from mature dendritic cells to T cells. Current Biology. (1999). , 9(1), 21-29.

[62] Izquierdo-useros, N, Naranjo-gómez, M, Erkizia, I, Puertas, M. C, Borràs, F. E, Blanco, J, et al. HIV and mature dendritic cells: Trojan exosomes riding the Trojan horse? PLoS Pathogens. (2010). e1000740.

[63] Turville, S, Wilkinson, J, Cameron, P, Dable, J, \& Cunningham, A. L. The role of dendritic cell C-type lectin receptors in HIV pathogenesis. Journal of Leukocyte Biology. (2003). , 74(5), 710-718.

[64] Freer, G, \& Matteucci, D. Influence of dendritic cells on viral pathogenicity. PLoS Pathogens. (2009). e1000384.

[65] Arrighi, J. F, Pion, M, Wiznerowicz, M, Geijtenbeek, T. B, Garcia, E, Abraham, S, et al. Lentivirus-mediated RNA interference of DC-SIGN expression inhibits human immunodeficiency virus transmission from dendritic cells to T cells. Journal of Virology. (2004). , 78(20), 10848-10855.

[66] Pohlmann, S, Baribaud, F, Lee, B, Leslie, G. J, Sanchez, M. D, Hiebenthal-millow, K, et al. DC-SIGN interactions with human immunodeficiency virus type 1 and 2 and simian immunodeficiency virus. Journal of Virology. (2001). , 75(10), 4664-4672.

[67] Vanham, G, Van Tendeloo, V, Willems, B, Penne, L, Kestens, L, Beirnaert, E, et al. The HIV-2 genotype and the HIV-1 syncytium-inducing phenotype are associated with a lower virus replication in dendritic cells. Journal of Medical Virology. (2000). , 60(3), 300-312.

[68] Duvall, M. G, Loré, K, Blaak, H, Ambrozak, D. A, Adams, W. C, Santos, K, et al. Dendritic cells are less susceptible to human immunodeficiency virus type 2 (HIV-2) infection than to HIV-1 infection. Journal of Virology. (2007). , 81(24), 13486-13498.

[69] Laguette, N, Sobhian, B, Casartelli, N, Ringeard, M, Chable-bessia, C, Ségéral, E, et al. SAMHD1 is the dendritic- and myeloid-cell-specific HIV-1 restriction factor counteracted by Vpx. Nature. (2011). , 474(7353), 654-657. 
[70] Hrecka, K, Hao, C, Gierszewska, M, Swanson, S. K, Kesik-brodacka, M, Srivastava, S, et al. Vpx relieves inhibition of HIV-1 infection of macrophages mediated by the SAMHD1 protein. Nature. (2011). , 474(7353), 658-661.

[71] Goldstone, D. C, Ennis-adeniran, V, Hedden, J. J, Groom, H. C, Rice, G. I, Christodoulou, E, et al. HIV-1 restriction factor SAMHD1 is a deoxynucleoside triphosphate triphosphohydrolase. Nature. (2011). , 480(7377), 379-382.

[72] Altfeld, M, Fadda, L, Frleta, D, \& Bhardwaj, N. DCs and NK cells: critical effectors in the immune response to HIV-1. Nature Reviews Immunology. (2011). , 11(3), 176-186.

[73] Manel, N, Hogstad, B, Wang, Y, Levy, D. E, Unutmaz, D, \& Littman, D. R. A cryptic sensor for HIV-1 activates antiviral innate immunity in dendritic cells. Nature. (2010). , 467(7312), 214-217.

[74] Manel, N, \& Littman, D. R. Hiding in plain sight: how HIV evades innate immune responses. Cell. (2011). , 147(2), 271-274.

[75] Lambotte, O, Boufassa, F, Madec, Y, Nguyen, A, Goujard, C, Meyer, L, et al. HIV controllers: a homogeneous group of HIV-1-infected patients with spontaneous control of viral replication. Clinical Infectious Diseases. (2005). , 41(7), 1053-1056.

[76] Esbjornsson, J, Mansson, F, Kvist, A, Isberg, P-E, Nowroozalizadeh, S, Biague, A. J, et al. Inhibition of HIV-1 disease progression by contemporaneous HIV-2 infection. The New England journal of medicine. (2012). , 367(3), 224-232.

[77] Cavaleiro, R, Sousa, A. E, Loureiro, A, \& Victorino, R. M. Marked immunosuppressive effects of the HIV-2 envelope protein in spite of the lower HIV-2 pathogenicity. AIDS. (2000). , 14(17), 2679-2686.

[78] Arhel, N, Lehmann, M, Clau, K, Nienhaus, G. U, Piguet, V, \& Kirchhoff, F. The inability to disrupt the immunological synapse between infected human $\mathrm{T}$ cells and APCs distinguishes HIV-1 from most other primate lentiviruses. Journal of Clinical Investigation. (2009). , 119(10), 2965-2975.

[79] Dalgleish, A. G, Beverley, P. C, Clapham, P. R, Crawford, D. H, Greaves, M. F, Weiss, R. A, \& The, C. D. T4) antigen is an essential component of the receptor for the AIDS retrovirus. Nature. (1984). , 312(5996), 763-767.

[80] Klatzmann, D, Champagne, E, Chamaret, S, Gruest, J, Guetard, D, Hercend, T, et al. T-lymphocyte T4 molecule behaves as the receptor for human retrovirus LAV. Nature. (1984). , 312(5996), 767-768.

[81] Clapham, P. R, \& Mcknight, A. Cell surface receptors, virus entry and tropism of primate lentiviruses. Journal of General Virology. (2002). Pt 8) 1809-1829.

[82] Doms, R. W, \& Trono, D. The plasma membrane as a combat zone in the HIV battlefield. Genes and Development. (2000). , 14(21), 2677-2688.

[83] Marsh, M, \& Helenius, A. Virus entry: open sesame. Cell. (2006). , 124(4), 729-740. 
[84] Daecke, J, Fackler, O. T, Dittmar, M. T, \& Krausslich, H. G. Involvement of clathrinmediated endocytosis in human immunodeficiency virus type 1 entry. Journal of Virology. (2005). , 79(3), 1581-1594.

[85] Miyauchi, K, Kim, Y, Latinovic, O, Morozov, V, \& Melikyan, G. B. HIV enters cells via endocytosis and dynamin-dependent fusion with endosomes. Cell. (2009). , 137(3), 433-444.

[86] Alkhatib, G, Combadiere, C, Broder, C. C, Feng, Y, Kennedy, P. E, Murphy, P. M, et al. CC CKR5: a RANTES, MIP-1alpha, MIP-1beta receptor as a fusion cofactor for macrophage-tropic HIV-1. Science. (1996). , 272(5270), 1955-1958.

[87] Feng, Y, Broder, C. C, Kennedy, P. E, \& Berger, E. A. HIV-1 entry cofactor: functional cDNA cloning of a seven-transmembrane, G protein-coupled receptor. Science. (1996). , 272(5263), 872-877.

[88] Broder, C. C, \& Jones-trower, A. Coreceptor use by primate Lentiviruses. In: Kuiken C, Foley BT, Hahn B, Korber B, McCutchan F, Marx PA, et al., (eds.) Human Retroviruses and AIDS: A Compilation and Analysis of Nucleic Acid and Amino Acid Sequences. Los Alamos, NM: Theoretical Biology and Biophysics Group, Los Alamos National Laboratory; (1999). , 517-541.

[89] Calado, M, Matoso, P, Santos-costa, Q, Espirito-santo, M, Machado, J, Rosado, L, et al. Coreceptor usage by HIV-1 and HIV-2 primary isolates: the relevance of CCR8 chemokine receptor as an alternative coreceptor. Virology. (2010). , 408(2), 174-182.

[90] Neil, S. J, Aasa-chapman, M. M, Clapham, P. R, Nibbs, R. J, Mcknight, A, \& Weiss, R. A. The promiscuous CC chemokine receptor D6 is a functional coreceptor for primary isolates of human immunodeficiency virus type 1 (HIV-1) and HIV-2 on astrocytes. Journal of Virology. (2005). , 79(15), 9618-9624.

[91] Shimizu, N, Tanaka, A, Oue, A, Mori, T, Ohtsuki, T, Apichartpiyakul, C, et al. Broad usage spectrum of $\mathrm{G}$ protein-coupled receptors as coreceptors by primary isolates of HIV. AIDS. (2009). , 27(7), 761-769.

[92] Simmons, G, Reeves, J, Hibbitts, S, Stine, J, Gray, P, Proudfoot, A, et al. Co-receptor use by HIV and inhibition of HIV infection by chemokine receptor ligands. Immunological Reviews. (2000). , 177-112.

[93] Zhang, Y. J, Dragic, T, Cao, Y, Kostrikis, L, Kwon, D. S, Littman, D. R, et al. Use of coreceptors other than CCR5 by non-syncytium-inducing adult and pediatric isolates of human immunodeficiency virus type 1 is rare in vitro. Journal of Virology. (1998). , 72(11), 9337-9344.

[94] Moore, J. P, Kitchen, S. G, Pugach, P, \& Zack, J. A. The CCR5 and CXCR4 coreceptors--central to understanding the transmission and pathogenesis of human immunodeficiency virus type 1 infection. AIDS Research and Human Retroviruses. (2004). , 20(1), 111-126. 
[95] Jiang, C, Parrish, N. F, Wilen, C. B, Li, H, Chen, Y, Pavlicek, J. W, et al. Primary infection by a human immunodeficiency virus with atypical coreceptor tropism. Journal of Virology. (2011). , 85(20), 10669-10681.

[96] Azevedo-pereira, J. M, Santos-costa, Q, Mansinho, K, \& Moniz-pereira, J. Identification and characterization of HIV-2 strains obtained from asymptomatic patients that do not use CCR5 or CXCR4 coreceptors. Virology. (2003). , 313(1), 136-146.

[97] Xiao, L, Rudolph, D. L, Owen, S. M, Spira, T. J, \& Lal, R. B. Adaptation to promiscuous usage of CC and CXC-chemokine coreceptors in vivo correlates with HIV-1 disease progression. AIDS. (1998). F, 137-143.

[98] Willey, S. J, Reeves, J. D, Hudson, R, Miyake, K, Dejucq, N, Schols, D, et al. Identification of a subset of human immunodeficiency virus type 1 (HIV-1), HIV-2, and simian immunodeficiency virus strains able to exploit an alternative coreceptor on untransformed human brain and lymphoid cells. Journal of Virology. (2003). , 77(11), 6138-6152.

[99] Pohlmann, S, Krumbiegel, M, \& Kirchhoff, F. Coreceptor usage of BOB/GPR15 and Bonzo/STRL33 by primary isolates of human immunodeficiency virus type 1. Journal of General Virology. (1999). Pt 5) 1241-1251.

[100] Lee, S, Tiffany, H. L, King, L, Murphy, P. M, Golding, H, \& Zaitseva, M. B. CCR8 on human thymocytes functions as a human immunodeficiency virus type 1 coreceptor. Journal of Virology. (2000). , 74(15), 6946-6952.

[101] Edinger, A. L, Hoffman, T. L, Sharron, M, Lee, B, Dowd, O, \& Doms, B. RW. Use of GPR1, GPR15, and STRL33 as coreceptors by diverse human immunodeficiency virus type 1 and simian immunodeficiency virus envelope proteins. Virology. (1998). , 249(2), 367-378.

[102] Deng, H. K, \& Unutmaz, D. KewalRamani VN, Littman DR. Expression cloning of new receptors used by simian and human immunodeficiency viruses. Nature. (1997). , 388(6639), 296-300.

[103] Cilliers, T, Willey, S, Sullivan, W. M, Patience, T, Pugach, P, Coetzer, M, et al. Use of alternate coreceptors on primary cells by two HIV-1 isolates. Virology. (2005). , 339(1), 136-144.

[104] Gharu, L, Ringe, R, \& Bhattacharya, J. Evidence of extended alternate coreceptor usage by HIV-1 clade C envelope obtained from an Indian patient. Virus Research. (2012). , 163(1), 410-414.

[105] Grivel, J-C, Shattock, R. J, \& Margolis, L. B. Selective transmission of R5 HIV-1 variants: where is the gatekeeper? Journal of Translational Medicine. (2011). Suppl 1 S6.

[106] Keele, B. F, \& Estes, J. D. Barriers to mucosal transmission of immunodeficiency viruses. Blood. (2011). , 118(4), 839-846. 
[107] Chalmet, K, Dauwe, K, Foquet, L, Baatz, F, Seguin-devaux, C, Van Der Gucht, B, et al. Presence of CXCR4-Using HIV-1 in Patients With Recently Diagnosed Infection: Correlates and Evidence for Transmission. Journal of Infectious Diseases. (2012). , 205(2), 174-184.

[108] Hedskog, C, Mild, M, \& Albert, J. Transmission of the X4 Phenotype of HIV-1: Is There Evidence Against the "Random Transmission" Hypothesis? Journal of Infectious Diseases. (2012). , 205(2), 163-165.

[109] Sol, N, Ferchal, F, Braun, J, Pleskoff, O, Treboute, C, Ansart, I, et al. Usage of the coreceptors CCR-5, CCR-3, and CXCR-4 by primary and cell line-adapted human immunodeficiency virus type 2. Journal of Virology. (1997). , 71(11), 8237-8244.

[110] Mcknight, A, Shotton, C, Cordell, J, Jones, I, Simmons, G, \& Clapham, P. R. Location, exposure, and conservation of neutralizing and nonneutralizing epitopes on human immunodeficiency virus type 2 SU glycoprotein. Journal of Virology. (1996). , 70(7), 4598-4606.

[111] Starcich, B. R, Hahn, B. H, Shaw, G. M, Mcneely, P. D, Modrow, S, Wolf, H, et al. Identification and characterization of conserved and variable regions in the envelope gene of HTLV-III/LAV, the retrovirus of AIDS. Cell. (1986). , 45(5), 637-648.

[112] Willey, R. L, Rutledge, R. A, Dias, S, Folks, T, Theodore, T, Buckler, C. E, et al. Identification of conserved and divergent domains within the envelope gene of the acquired immunodeficiency syndrome retrovirus. Proceedings of the National Academy of Sciences of the United States of America. (1986). , 83(14), 5038-5042.

[113] Cho, M. W, Lee, M. K, Carney, M. C, Berson, J. F, Doms, R. W, \& Martin, M. A. Identification of determinants on a dualtropic human immunodeficiency virus type 1 envelope glycoprotein that confer usage of CXCR4. Journal of Virology. (1998). , 72(3), 2509-2515.

[114] Hoffman, T. L, \& Doms, R. W. HIV-1 envelope determinants for cell tropism and chemokine receptor use. Molecular Membrane Biology. (1999). , 16(1), 57-65.

[115] Hoffman, T. L, Stephens, E. B, Narayan, O, \& Doms, R. W. HIV type I envelope determinants for use of the CCR2b, CCR3, STRL33, and APJ coreceptors. Proceedings of the National Academy of Sciences of the United States of America. (1998). , 95(19), 11360-11365.

[116] Hu, Q, Trent, J. O, Tomaras, G. D, Wang, Z, Murray, J. L, Conolly, S. M, et al. Identification of ENV determinants in that influence the molecular anatomy of CCR5 utilization. Journal of Molecular Biology. (2000). , 3

[117] Smyth, R. J, Yi, Y, Singh, A, \& Collman, R. G. Determinants of entry cofactor utilization and tropism in a dualtropic human immunodeficiency virus type 1 primary isolate. Journal of Virology. (1998). , 72(5), 4478-4484. 
[118] Briggs, D. R, Tuttle, D. L, Sleasman, J. W, Goodenow, M. M, \& Envelope, V. amino acid sequence predicts HIV-1 phenotype (co-receptor usage and tropism for macrophages). AIDS. (2000). , 14(18), 2937-2939.

[119] Delobel, P, Nugeyre, M. T, Cazabat, M, Pasquier, C, Marchou, B, Massip, P, et al. Population-based sequencing of the region of env for predicting the coreceptor usage of human immunodeficiency virus type 1 quasispecies. Journal of Clinical Microbiology. (2007). , 3

[120] Kwong, P. D, Wyatt, R, Robinson, J, Sweet, R. W, Sodroski, J, \& Hendrickson, W. A. Structure of an HIV gp120 envelope glycoprotein in complex with the CD4 receptor and a neutralizing human antibody. Nature. (1998). , 393(6686), 648-659.

[121] Labrosse, B, Treboute, C, Brelot, A, \& Alizon, M. Cooperation of the V2 and V3 domains of human immunodeficiency virus type 1 gp120 for interaction with the CXCR4 receptor. Journal of Virology. (2001). , 1

[122] Nabatov, A. A, Pollakis, G, Linnemann, T, Kliphius, A, Chalaby, M. I, \& Paxton, W. A. Intrapatient alterations in the human immunodeficiency virus type 1 gp120 and V3 regions differentially modulate coreceptor usage, virus inhibition by CC/CXC chemokines, soluble CD4, and the b12 and 2G12 monoclonal antibodies. Journal of Virology. (2004). , 1V2

[123] Pollakis, G, Kang, S, Kliphuis, A, Chalaby, M. I, \& Goudsmit, J. Paxton WA. N-linked glycosylation of the HIV type-1 gp120 envelope glycoprotein as a major determinant of CCR5 and CXCR4 coreceptor utilization. Journal of Biological Chemistry. (2001). , 276(16), 13433-13441.

[124] Wyatt, R, Moore, J, Accola, M, Desjardin, E, Robinson, J, \& Sodroski, J. Involvement of the V2 variable loop structure in the exposure of human immunodeficiency virus type 1 gp120 epitopes induced by receptor binding. Journal of Virology. (1995). , 1

[125] Santos-costa, Q, Mansinho, K, Moniz-pereira, J, \& Azevedo-pereira, J. M. Characterization of HIV-2 chimeric viruses unable to use CCR5 and CXCR4 coreceptors. Virus Research. (2009).

[126] De Silva, T. I, Aasa-chapman, M, Cotten, M, Hué, S, Robinson, J, Bibollet-ruche, F, et al. Potent Autologous and Heterologous Neutralizing Antibody Responses Occur in HIV-2 Infection across a Broad Range of Infection Outcomes. Journal of Virology. (2012). , 86(2), 930-946.

[127] Kong, R, Li, H, Bibollet-ruche, F, Decker, J. M, Zheng, N. N, Gottlieb, G. S, et al. Broad and Potent Neutralizing Antibody Responses Elicited in Natural HIV-2 Infection. Journal of Virology. (2012). , 86(2), 947-960.

[128] Marcelino, J. M, Borrego, P, Rocha, C, Barroso, H, Quintas, A, Novo, C, et al. Potent and Broadly Reactive HIV-2 Neutralizing Antibodies Elicited by a Vaccinia Virus 
Vector Prime-C2Polypeptide Boost Immunization Strategy. Journal of Virology. (2010). , 3C3

[129] Ozkaya Sahin GHolmgren B, da Silva Z, Nielsen J, Nowroozalizadeh S, Esbjörnsson $\mathrm{J}$, et al. Potent Intratype Neutralizing Activity Distinguishes Human Immunodeficiency Virus Type 2 (HIV-2) from HIV-1. Journal of Virology. (2012). , 86(2), 961-971.

[130] Bjorling, E, Broliden, K, Bernardi, D, Utter, G, Thorstensson, R, Chiodi, F, et al. Hyperimmune antisera against synthetic peptides representing the glycoprotein of human immunodeficiency virus type 2 can mediate neutralization and antibodydependent cytotoxic activity. Proceedings of the National Academy of Sciences of the United States of America. (1991). , 88(14), 6082-6086.

[131] Bjorling, E, Chiodi, F, Utter, G, \& Norrby, E. Two neutralizing domains in the region in the envelope glycoprotein gp125 of HIV type 2. Journal of Immunology. (1994). , 3

[132] Matsushita, S, Matsumi, S, Yoshimura, K, Morikita, T, Murakami, T, \& Takatsuki, K. Neutralizing monoclonal antibodies against human immunodeficiency virus type 2 gp120. Journal of Virology. (1995). , 69(6), 3333-3340.

[133] Albert, J, Stalhandske, P, Marquina, S, Karis, J, Fouchier, R. A, Norrby, E, et al. Biological phenotype of HIV type 2 isolates correlates with genotype. AIDS Research and Human Retroviruses. (1996). , 3

[134] Isaka, Y, Sato, A, Miki, S, Kawauchi, S, Sakaida, H, Hori, T, et al. Small amino acid changes in the loop of human immunodeficiency virus type 2 determines the coreceptor usage for CXCR4 and CCR5. Virology. (1999). , 3

[135] Morner, A, Thomas, J. A, Bjorling, E, Munson, P. J, Lucas, S. B, \& Mcknight, A. Productive HIV-2 infection in the brain is restricted to macrophages/microglia. AIDS. (2003). , 17(10), 1451-1455.

[136] Shi, Y, Brandin, E, Vincic, E, Jansson, M, Blaxhult, A, Gyllensten, K, et al. Evolution of human immunodeficiency virus type 2 coreceptor usage, autologous neutralization, envelope sequence and glycosylation. Journal of General Virology. (2005). Pt 12) 3385-3396.

[137] Visseaux, B, Hurtado-nedelec, M, Charpentier, C, Collin, G, Storto, A, Matheron, S, et al. Molecular Determinants of HIV-2 R5-X4 Tropism in the Loop: Development of a New Genotypic Tool. Journal of Infectious Diseases. (2012). , 3

[138] Kulkarni, S, Tripathy, S, Agnihotri, K, Jatkar, N, Jadhav, S, Umakanth, W, et al. Indian primary HIV-2 isolates and relationship between genotype, biological phenotype and coreceptor usage. Virology. (2005). , 3

[139] Owen, S. M, Ellenberger, D, Rayfield, M, Wiktor, S, Michel, P, Grieco, M. H, et al. Genetically divergent strains of human immunodeficiency virus type 2 use multiple coreceptors for viral entry. Journal of Virology. (1998). , 72(7), 5425-5432. 
[140] Santos-costa, Q, Parreira, R, Moniz-pereira, J, \& Azevedo-pereira, J. M. Molecular characterization of the env gene of two CCR5/CXCR4-independent human immunodeficiency 2 primary isolates. Journal of Medical Virology. (2009). , 81(11), 1869-1881.

[141] Blaak, H, Van Der Ende, M. E, Boers, P. H, Schuitemaker, H, \& Osterhaus, A. D. In vitro replication capacity of HIV-2 variants from long-term aviremic individuals. Virology. (2006). , 353(1), 144-154.

[142] Baggiolini, M, Dewald, B, \& Moser, B. Human chemokines: an update. Annual Review of Immunology. (1997). , 15-675.

[143] Bleul, C. C, Wu, L, Hoxie, J. A, Springer, T. A, \& Mackay, C. R. The HIV coreceptors CXCR4 and CCR5 are differentially expressed and regulated on human T lymphocytes. Proceedings of the National Academy of Sciences of the United States of America. (1997). , 94(5), 1925-1930.

[144] Wu, L, Paxton, W. A, Kassam, N, Ruffing, N, Rottman, J. B, Sullivan, N, et al. CCR5 levels and expression pattern correlate with infectability by macrophage-tropic HIV-1, in vitro. Journal of Experimental Medicine. (1997). , 185(9), 1681-1691.

[145] Woods, T. C, Roberts, B. D, Butera, S. T, \& Folks, T. M. Loss of inducible virus in CD45RA naive cells after human immunodeficiency virus-1 entry accounts for preferential viral replication in CD45RO memory cells. Blood. (1997). , 89(5), 1635-1641.

[146] Azevedo-pereira, J. M, Santos-costa, Q, \& Moniz-pereira, J. HIV-2 infection and chemokine receptors usage- clues to reduced virulence of HIV-2. Current HIV Research. (2005). , 3(1), 3-16.

[147] Reeves, J. D, \& Doms, R. W. Human immunodeficiency virus type 2. Journal of General Virology. (2002). Pt 6) 1253-1265.

[148] Willey, S, Roulet, V, Reeves, J. D, Kergadallan, M. L, Thomas, E, Mcknight, A, et al. Human Leydig cells are productively infected by some HIV-2 and SIV strains but not by HIV-1. AIDS. (2003). , 17(2), 183-188.

[149] Wu, Y, \& Yoder, A. Chemokine coreceptor signaling in HIV-1 infection and pathogenesis. PLoS Pathogens. (2009). e1000520.

[150] Kozak, S. L, Platt, E. J, Madani, N, \& Ferro, F. E. Jr, Peden K, Kabat D. CD4, CXCR-4, and CCR-5 dependencies for infections by primary patient and laboratory-adapted isolates of human immunodeficiency virus type 1. Journal of Virology. (1997). , 71(2), 873-882.

[151] Kuhmann, S. E, Platt, E. J, Kozak, S. L, \& Kabat, D. Cooperation of multiple CCR5 coreceptors is required for infections by human immunodeficiency virus type 1 . Journal of Virology. (2000). , 74(15), 7005-7015.

[152] Lee, B, Sharron, M, Montaner, L. J, Weissman, D, \& Doms, R. W. Quantification of CD4, CCR5, and CXCR4 levels on lymphocyte subsets, dendritic cells, and differen- 
tially conditioned monocyte-derived macrophages. Proceedings of the National Academy of Sciences of the United States of America. (1999). , 96(9), 5215-5220.

[153] Platt, E. J, Wehrly, K, Kuhmann, S. E, Chesebro, B, \& Kabat, D. Effects of CCR5 and CD4 cell surface concentrations on infections by macrophagetropic isolates of human immunodeficiency virus type 1. Journal of Virology. (1998). , 72(4), 2855-2864.

[154] Naif, H. M, Li, S, Alali, M, Sloane, A, Wu, L, Kelly, M, et al. CCR5 expression correlates with susceptibility of maturing monocytes to human immunodeficiency virus type 1 infection. Journal of Virology. (1998). , 72(1), 830-836.

[155] Tuttle, D. L, Harrison, J. K, Anders, C, Sleasman, J. W, \& Goodenow, M. M. Expression of CCR5 increases during monocyte differentiation and directly mediates macrophage susceptibility to infection by human immunodeficiency virus type 1 . Journal of Virology. (1998). , 72(6), 4962-4969.

[156] Roos, R. S, Loetscher, M, Legler, D. F, Clark-lewis, I, Baggiolini, M, \& Moser, B. Identification of CCR8, the receptor for the human CC chemokine I-309. Journal of Biological Chemistry. (1997). , 272(28), 17251-17254.

[157] Tiffany, H. L, Lautens, L. L, Gao, J. L, Pease, J, Locati, M, Combadiere, C, et al. Identification of CCR8: a human monocyte and thymus receptor for the CC chemokine I-309. Journal of Experimental Medicine. (1997). , 186(1), 165-170.

[158] Ambrosio, D, Iellem, D, Bonecchi, A, Mazzeo, R, Sozzani, D, \& Mantovani, S. A, et al. Selective up-regulation of chemokine receptors CCR4 and CCR8 upon activation of polarized human type 2 Th cells. Journal of Immunology. (1998). , 161(10), 5111-5115.

[159] Zingoni, A, Soto, H, Hedrick, J. A, Stoppacciaro, A, Storlazzi, C. T, Sinigaglia, F, et al. The chemokine receptor CCR8 is preferentially expressed in Th2 but not Th1 cells. Journal of Immunology. (1998). , 161(2), 547-551.

[160] Horuk, R, Hesselgesser, J, Zhou, Y, Faulds, D, Halks-miller, M, Harvey, S, et al. The CC chemokine I-309 inhibits CCR8-dependent infection by diverse HIV-1 strains. Journal of Biological Chemistry. (1998). , 273(1), 386-391.

[161] Connor, R. I, Sheridan, K. E, Ceradini, D, Choe, S, \& Landau, N. R. Change in coreceptor use coreceptor use correlates with disease progression in HIV-1--infected individuals. Journal of Experimental Medicine. (1997). , 185(4), 621-628.

[162] van'Wout, t, Blaak, A. B, Ran, H, Brouwer, L. J, Kuiken, M, \& Schuitemaker, C. H. Evolution of syncytium-inducing and non-syncytium-inducing biological virus clones in relation to replication kinetics during the course of human immunodeficiency virus type 1 infection. Journal of Virology. (1998). , 72(6), 5099-5107.

[163] Berkowitz, R. D, Beckerman, K. P, Schall, T. J, \& Mccune, J. M. CXCR4 and CCR5 expression delineates targets for HIV-1 disruption of T cell differentiation. Journal of Immunology. (1998). , 161(7), 3702-3710. 
[164] Kitchen, S. G, \& Zack, J. A. CXCR4 expression during lymphopoiesis: implications for human immunodeficiency virus type 1 infection of the thymus. Journal of Virology. (1997). , 71(9), 6928-6934.

[165] Taylor, J. R. Jr., Kimbrell KC, Scoggins R, Delaney M, Wu L, Camerini D. Expression and function of chemokine receptors on human thymocytes: implications for infection by human immunodeficiency virus type 1. Journal of Virology. (2001). , 75(18), 8752-8760.

[166] Guillon, C, Van Der Ende, M. E, Boers, P. H, Gruters, R. A, Schutten, M, \& Osterhaus, A. D. Coreceptor usage of human immunodeficiency virus type 2 primary isolates and biological clones is broad and does not correlate with their syncytium-inducing capacities. Journal of Virology. (1998). , 72(7), 6260-6263.

[167] Mcknight, A, Dittmar, M. T, Moniz-periera, J, Ariyoshi, K, Reeves, J. D, Hibbitts, S, et al. A broad range of chemokine receptors are used by primary isolates of human immunodeficiency virus type 2 as coreceptors with CD4. Journal of Virology. (1998). , 72(5), 4065-4071.

[168] Reeves, J. D, Hibbitts, S, Simmons, G, Mcknight, A, Azevedo-pereira, J. M, Monizpereira, J, et al. Primary human immunodeficiency virus type 2 (HIV-2) isolates infect CD4-negative cells via CCR5 and CXCR4: comparison with HIV-1 and simian immunodeficiency virus and relevance to cell tropism in vivo. Journal of Virology. (1999). , 73(9), 7795-7804.

[169] Dumonceaux, J, Nisole, S, Chanel, C, Quivet, L, Amara, A, Baleux, F, et al. Spontaneous mutations in the env gene of the human immunodeficiency virus type 1 NDK isolate are associated with a CD4-independent entry phenotype. Journal of Virology. (1998). , 72(1), 512-519.

[170] Hoffman, T. L. LaBranche CC, Zhang W, Canziani G, Robinson J, Chaiken I, et al. Stable exposure of the coreceptor-binding site in a CD4-independent HIV- 1 envelope protein. Proceedings of the National Academy of Sciences of the United States of America. (1999). , 96(11), 6359-6364.

[171] Kolchinsky, P, Mirzabekov, T, Farzan, M, Kiprilov, E, Cayabyab, M, Mooney, L. J, et al. Adaptation of a CCR5-using, primary human immunodeficiency virus type 1 isolate for CD4-independent replication. Journal of Virology. (1999). , 73(10), 8120-8126.

[172] LaBranche CCHoffman TL, Romano J, Haggarty BS, Edwards TG, Matthews TJ, et al. Determinants of CD4 independence for a human immunodeficiency virus type 1 variant map outside regions required for coreceptor specificity. Journal of Virology. (1999). , 73(12), 10310-10319.

[173] Xiao, P, Usami, O, Suzuki, Y, Ling, H, Shimizu, N, Hoshino, H, et al. Characterization of a CD4-independent clinical HIV-1 that can efficiently infect human hepatocytes through chemokine (C-X-C motif) receptor 4. AIDS. (2008). , 22(14), 1749-1757. 
[174] Zerhouni, B, Nelson, J. A, \& Saha, K. Isolation of CD4-independent primary human immunodeficiency virus type 1 isolates that are syncytium inducing and acutely cytopathic for CD8+ lymphocytes. Journal of Virology. (2004). , 78(3), 1243-1255.

[175] Saha, K, Zhang, J, Gupta, A, Dave, R, Yimen, M, \& Zerhouni, B. Isolation of primary HIV-1 that target CD8+ T lymphocytes using CD8 as a receptor. Nature Medicine. (2001). , 7(1), 65-72.

[176] Azevedo-pereira, J. M, Santos-costa, Q, Taveira, N, Verissimo, F, \& Moniz-pereira, J. Construction and characterization of CD4-independent infectious recombinant HIV-2 molecular clones. Virus Research. (2003). , 97(2), 159-163.

[177] Edinger, A. L, Mankowski, J. L, Doranz, B. J, Margulies, B. J, Lee, B, Rucker, J, et al. CD4-independent, CCR5-dependent infection of brain capillary endothelial cells by a neurovirulent simian immunodeficiency virus strain. Proceedings of the National Academy of Sciences of the United States of America. (1997). , 94(26), 14742-14747.

[178] Endres, M. J, Clapham, P. R, Marsh, M, Ahuja, M, Turner, J. D, Mcknight, A, et al. CD4-independent infection by HIV-2 is mediated by fusin/CXCR4. Cell. (1996). , 87(4), 745-756.

[179] Liu, H. Y, Soda, Y, Shimizu, N, Haraguchi, Y, Jinno, A, Takeuchi, Y, et al. CD4-Dependent and CD4-independent utilization of coreceptors by human immunodeficiency viruses type 2 and simian immunodeficiency viruses. Virology. (2000). , 278(1), 276-288.

[180] Gorry, P. R, Taylor, J, Holm, G. H, Mehle, A, Morgan, T, Cayabyab, M, et al. Increased CCR5 affinity and reduced CCR5/CD4 dependence of a neurovirulent primary human immunodeficiency virus type 1 isolate. Journal of Virology. (2002). , 76(12), 6277-6292.

[181] Marras, D, Bruggeman, L. A, Gao, F, Tanji, N, Mansukhani, M. M, Cara, A, et al. Replication and compartmentalization of HIV-1 in kidney epithelium of patients with HIV-associated nephropathy. Nature Medicine. (2002). , 8(5), 522-526.

[182] Edwards, T. G, Hoffman, T. L, Baribaud, F, \& Wyss, S. LaBranche CC, Romano J, et al. Relationships between CD4 independence, neutralization sensitivity, and exposure of a CD4-induced epitope in a human immunodeficiency virus type 1 envelope protein. Journal of Virology. (2001). , 75(11), 5230-5239.

[183] Reeves, J. D, Schulz, T. F, \& The, C. D. independent tropism of human immunodeficiency virus type 2 involves several regions of the envelope protein and correlates with a reduced activation threshold for envelope-mediated fusion. Journal of Virology. (1997). , 71(2), 1453-1465.

[184] Ugolini, S, Mondor, I, \& Sattentau, Q. J. HIV-1 attachment: another look. Trends in Microbiology. (1999). , 7(4), 144-149. 
[185] Bhattacharya, J, Peters, P. J, \& Clapham, P. R. CDindependent infection of HIV and SIV: implications for envelope conformation and cell tropism in vivo. AIDS. (2003). Suppl 4 S35-43., 4.

[186] Kolchinsky, P, Kiprilov, E, \& Sodroski, J. Increased neutralization sensitivity of CD4independent human immunodeficiency virus variants. Journal of Virology. (2001). , 75(5), 2041-2050.

[187] Puffer, B. A, Pohlmann, S, Edinger, A. L, Carlin, D, Sanchez, M. D, Reitter, J, et al. CD4 independence of simian immunodeficiency virus Envs is associated with macrophage tropism, neutralization sensitivity, and attenuated pathogenicity. Journal of Virology. (2002). , 76(6), 2595-2605.

[188] Thomas, E. R, Shotton, C, Weiss, R. A, Clapham, P. R, Mcknight, A, \& Hiv-2, C. D4-d. e. p. e. n. d. e. n. t a. n. d C. D4-i.n. d. e. p. e. n. d. e. n. t. consequences for neutralization. AIDS. (2003). , 17(3), 291-300.

[189] Zhang, P. F, Bouma, P, Park, E. J, Margolick, J. B, Robinson, J. E, Zolla-pazner, S, et al. A variable region 3 (mutation determines a global neutralization phenotype and CD4-independent infectivity of a human immunodeficiency virus type 1 envelope associated with a broadly cross-reactive, primary virus-neutralizing antibody response. Journal of Virology. (2002). , 3

[190] Bjorling, E, Scarlatti, G, Von Gegerfelt, A, Albert, J, Biberfeld, G, Chiodi, F, et al. Autologous neutralizing antibodies prevail in HIV-2 but not in HIV-1 infection. Virology. (1993). , 193(1), 528-530. 
